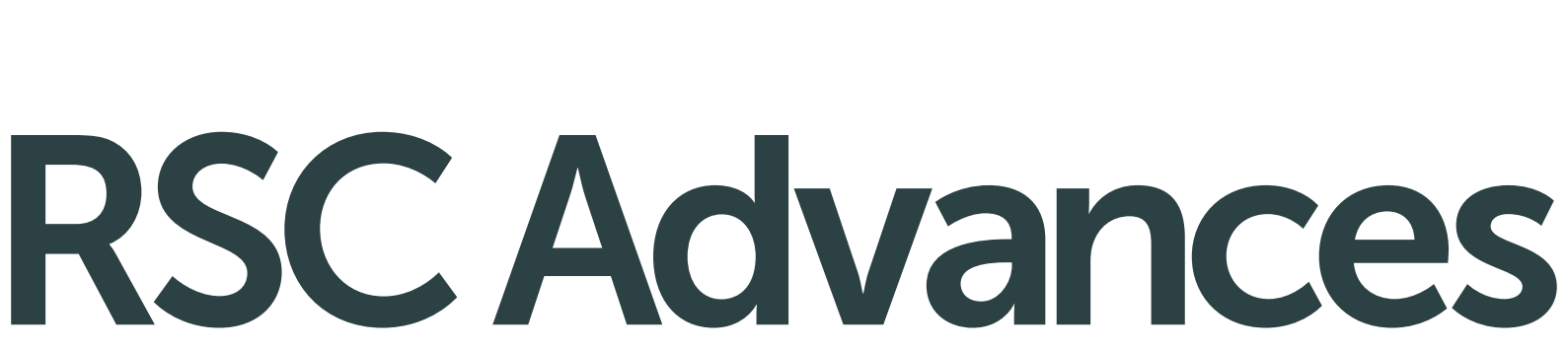

This article can be cited before page numbers have been issued, to do this please use: A. Orte, E. Debroye, M. J. Ruedas-Rama, E. Garcia-Fernandez, D. Robinson, L. Crovetto, E. M. Talavera, J. M. Alvarez-Pez, V. Leen, B. Verbelen, L. C. D. Rezende, W. Dehaen, J. Hofkens, M. Van der Auweraer and N. Boens, RSC Adv., 2016, DOI: 10.1039/C6RA22340K.

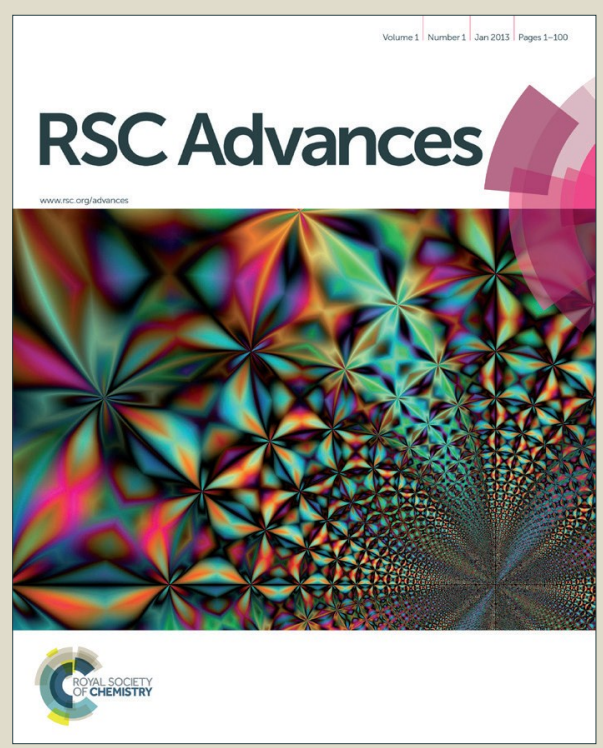

This is an Accepted Manuscript, which has been through the Royal Society of Chemistry peer review process and has been accepted for publication.

Accepted Manuscripts are published online shortly after acceptance, before technical editing, formatting and proof reading. Using this free service, authors can make their results available to the community, in citable form, before we publish the edited article. This Accepted Manuscript will be replaced by the edited, formatted and paginated article as soon as this is available.

You can find more information about Accepted Manuscripts in the Information for Authors.

Please note that technical editing may introduce minor changes to the text and/or graphics, which may alter content. The journal's standard Terms \& Conditions and the Ethical guidelines still apply. In no event shall the Royal Society of Chemistry be held responsible for any errors or omissions in this Accepted Manuscript or any consequences arising from the use of any information it contains. 


\title{
Effect of the substitution position $(2,3$ or 8$)$ on the spectroscopic and photophysical properties of BODIPY dyes with a phenyl, styryl or phenylethynyl group
}

\author{
Angel Orte, ${ }^{+, a}$ Elke Debroye, ${ }^{b}$ María J. Ruedas-Rama, ${ }^{a}$ Emilio Garcia-Fernandez, ${ }^{\text {a }}$ David Robinson, ${ }^{c}$ Luis \\ Crovetto, ${ }^{a}$ Eva M. Talavera, ${ }^{a}$ Jose M. Alvarez-Pez, ${ }^{a}$ Volker Leen, ${ }^{b}$ Bram Verbelen, ${ }^{b}$ Lucas Cunha Dias de \\ Rezende, ${ }^{b, d}$ Wim Dehaen, ${ }^{b}$ Johan Hofkens, ${ }^{b}$ Mark Van der Auweraer ${ }^{b}$ and Noël Boens ${ }^{\dagger, b}$
}

ABSTRACT. A very active branch of organic chemistry is putting great effort in tailoring fluorescent dyes for a myriad of applications, from technological to bioanalytical and biomedical applications. Among the major families of fluorophores, those derived from 4,4-difluoro-4bora-3a,4a-diaza-s-indacene (BODIPY dyes) are undergoing a recent boost thanks to the simplicity and robustness of the chemistry involved. The BODIPY core can be modified with numerous side groups, the 8-position being a modification place with important effects on the spectroscopic and photophysical properties of the resulting dyes. Likewise, previous work has shown that the addition of groups attached at the 3- and 2-positions can result in dyes with very different properties. Herein, we generalize the effect of the substituent side groups by studying nine BODIPY dyes substituted with a phenyl, styryl or phenylethynyl moiety at the 2-, 3- or 8-position of the BODIPY scaffold. Within the class of phenyl- or phenylethynyl-substituted dyes, substitution at the 2-position always leads to dyes with the broadest bandwidths and the largest Stokes shifts. We investigate the solvent effect on the spectroscopic properties of the dyes, using four empirical solvent scales (dipolarity, polarizability, acidity and basicity: Catalán, J. Phys. Chem., 2009, 113, 5951). These analyses identify solvent dipolarity and polarizability as critical parameters accounting for the observed solvent-dependent shifts of the absorption and emission maxima. Finally, time-dependent density functional theory calculations provide insights into the structural and energetic issues concerning the spectroscopic properties of these fluorophores.

KEYWORDS: Fluorescent dyes, solvent effect, Catalán solvent scales, quantum chemical calculations

\footnotetext{
Department of Physical Chemistry, Faculty of Pharmacy, University of Granada, Cartuja Campus, 18071 Granada, Spain. Department of Chemistry, KU Leuven (Katholieke Universiteit Leuven), Celestijnenlaan 200f, 3001 Leuven, Belgium.

School of Chemistry, University Of Nottingham, University Park, Nottingham, NG7 2RD, United Kingdom.

Faculdade de Ciências Farmacêuticas de Ribeirão Preto, Universidade de São Paulo, Av. Do Café s/n, Ribeirão Preto, SP, 14040-903, Brazil. + Corresponding authors: AO: E-mail: angelort@ugr.es, tel. +34-958243825. NB, E-mail: Noel.Boens@kuleuven.be

Electronic Supplementary Information (ESI) available: Figures S1-S14, Tables S1-S6, details on the spectral features of 2-Styryl and 8-Styryl, and details
} on the solvatochroism study. See DOI: 10.1039/x0xx00000x 


\section{Introduction}

The family of 4,4-difluoro-4-bora-3a,4a-diaza-s-indacene derivatives, better known as BODIPY (boron dipyrromethene or boron dipyrrin ${ }^{1-3}$, Chart 1) dyes, entail a rapidly growing class of compounds, characterized by extremely favorable fluorescent features, such as tunable excitation/emission wavelengths in the visible spectral range, narrow spectral bandwidths and good (photo)chemical stability. Likewise, relatively high molar absorption coefficient, $\varepsilon(\lambda)$, and fluorescence quantum yield, $\Phi$, values lead to a high brightness of these dyes. ${ }^{4} \mathrm{~A}$ very active branch of scientific development is putting great effort in fine-tuning the BODIPY properties by introducing suitable chemical groups onto the central core. As a result, the BODIPY family is expanding constantly and has found applications in wide-ranging fields, from technological (organic light-emitting diodes, ${ }^{5-7}$ dye-sensitized solar cells ${ }^{8-9}$ ) to analytical and in vivo imaging applications. ${ }^{10-11}$

Recent advances in organic synthesis have expanded the possibilities of controlled modification of the BODIPY moiety, including substitution by tailored groups at every position of the core. ${ }^{12}$ The direct conjugation of fused $\pi$ systems, extended $\pi$-bonds, the addition of alkyl or aryl groups, or the insertion of electron withdrawing or donating substituents have different effects on the spectroscopic and photophysical properties of the resulting dyes [fluorescence quantum yield $(\Phi)$ and lifetime $(\tau)$, absorption and emission energies $\left(\lambda_{\text {abs }}\right.$ and $\left.\lambda_{\text {em }}\right)$, Stokes shift $(\Delta \bar{v})$, full width at half maximum of the absorption and emission band ( $\mathrm{fwhm}_{\mathrm{abs}}$ and fwhm $\mathrm{em}$ ), etc.]. For instance, fusing rigid $\pi$-conjugated carbocycles to the BODIPY core results in near-infrared emitting dyes. ${ }^{13-16}$

Modification at the 8- (or meso-) position (Chart 1) results in a variety of substituent-promoted effects, as quantum chemical calculations have demonstrated the presence of a node in the HOMO at this position and a significant increase of the electron density upon excitation. ${ }^{17}$ Alkylation at the meso-position usually has a mild effect, resulting in boron dipyrromethenes with emission maxima around $500 \mathrm{~nm}$ and large fluorescence quantum yield values. ${ }^{17-18}$ Nevertheless, we recently found that a tert-butyl group at the 8- position causes an important decrease in the fluorescence quantum yield $\Phi$ and lifetime $\tau$ of the resulting dye, as well as a significant red shift of the fluorescence and, consequently, a striking $1560 \mathrm{~cm}^{-1}$ Stokes shift $\Delta \bar{v}$, much larger than those of other meso-alkylated analogues. ${ }^{19}$ Boron dipyrromethenes, modified at the meso-position with strong electron withdrawing groups, possess large red shifts, ${ }^{20-21}$ because the LUMO is highly stabilized ${ }^{3}$ compared to unsubstituted BODIPY. ${ }^{3,22-24}$ In contrast, electron donating groups at the meso-position cause a blue-shift in the absorption and emission spectra, while keeping high fluorescence quantum yields and lifetimes. ${ }^{25-28}$ Certain modifications at the meso-position may result in almost nonfluorescent compounds, as for meso-alkenyl- ${ }^{29}$ or meso-formylBODIPYs. ${ }^{30}$ Likewise, a meso-phenylBODIPY dye is also weakly fluorescent. ${ }^{31-32}$ However, mesophenylBODIPYs can display bright fluorescence, depending on the dihedral angle and steric hindrance of the rotation of the phenyl group with respect to the BODIPY core plane. For instance, while phenyl or $p$-tertbutylphenyl substituents at the meso-position cause low $\Phi$ and $\tau$ values, $o$-tolyl- or mesityl groups result in boron dipyrromethene dyes with high $\Phi(>0.90) .{ }^{32}$ The enhanced nonradiative deactivation in 8-phenyl- or $p$-tertbutylphenyl-substituted BODIPYs is attributed to the population of a distorted conformation of the BODIPY framework in the excited state, leading to loss of planarity. ${ }^{32}$ Another example of the effect of the dihedral angle of the meso-phenyl substituent on the fluorescence properties of the dyes can be found in the comparison between meso-phenyl-3,5-dimethylBODIPY, ${ }^{33}$ meso- $p$-methylphenyl-3,5-dimethylBODIPY and meso- $p$ methylphenyl-1,3,5,7-tetramethylBODIPY. ${ }^{34}$ While the 3,5-dimethyl substitution gives rise to moderate $\Phi$ values (0.17-0.42 for meso-phenyl- and 0.11-0.29 for meso-p-methylphenyl-substituted boron dipyrromethenes, depending on the solvent), the addition of two methyl groups at the positions 1- and 7- causes an increase in the fluorescence, with $\Phi$ up to the range 0.46-0.72. ${ }^{34}$

Although substituents at the 8-position have normally the largest effect on the photophysical properties of BODIPY derivatives, modifications at the 3- and 2-positions also give rise to dyes with diverse properties. Extending the conjugation with double bonds at the 3-position yields fluorophores with a high brightness. However, when the conjugation of the BODIPY framework is extended at the 2-position, dyes with a large Stokes shift $\Delta \bar{v}$, but lower $\Phi$ value, are obtained. In a preliminary study, our group described this effect for styryl and triazolyl substituents introduced at either the 3- or the 2-position. ${ }^{35}$ 


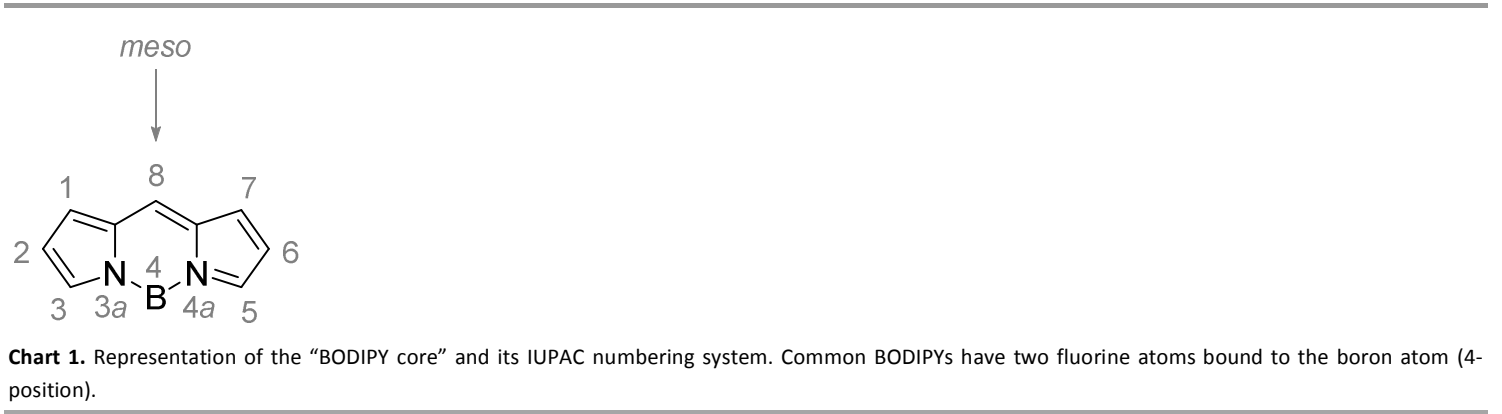

In this work, we generalize the effect of the substituent at the 2-, 3- or 8- position of the BODIPY core. Hence, we investigate nine 4,4-difluoro-4-bora-3a,4a-diaza-s-indacene dyes substituted with a phenylethynyl or styryl moiety at the 2, 3 or 8-position (2-Ethyn, 3-Ethyn, 8-Ethyn, 2-Styryl, 3-Styryl and 8-Styryl), a p-tert-butylphenyl group at the 2- or 3-position (2-Ph and 3-Ph) and phenyl at the 8-position (8-Ph) (Chart 2). The full characterization of the 8-phenylethynyl derivative (8-Ethyn) has been reported previously ${ }^{27}$ and has been included for discussion purposes. The spectroscopic and photophysical characteristics of these compounds have been investigated in a series of solvents by UV-vis spectrophotometry and steady-state and time-resolved fluorescence spectroscopy. These experiments allow us to determine the relevant spectroscopic and photophysical properties: spectral shape and maxima $\left[\lambda_{\text {abs }}(\max )\right.$ and $\lambda_{\text {em }}(\max ]$, Stokes shifts $(\Delta \bar{v})$, bandwidths $\left(f_{w h m}\right.$ abs and $\left.f w h m_{e m}\right)$, fluorescence quantum yields $(\Phi)$, fluorescence lifetimes $(\tau)$ and rate constants of fluorescence $\left(k_{\mathrm{f}}\right)$ and nonradiative $\left(k_{\mathrm{nr}}\right)$ deactivation processes. We investigate the solvent effect on the spectroscopic properties of the dyes, according to a generalized procedure based on a set of four empirical solvent scales: dipolarity, polarizability, acidity and basicity of the medium. ${ }^{36}$ Time-dependent density functional theory (TD-DFT) calculations provide insights into the structural and energetic properties concerning the spectroscopic parameters of the dyes investigated.
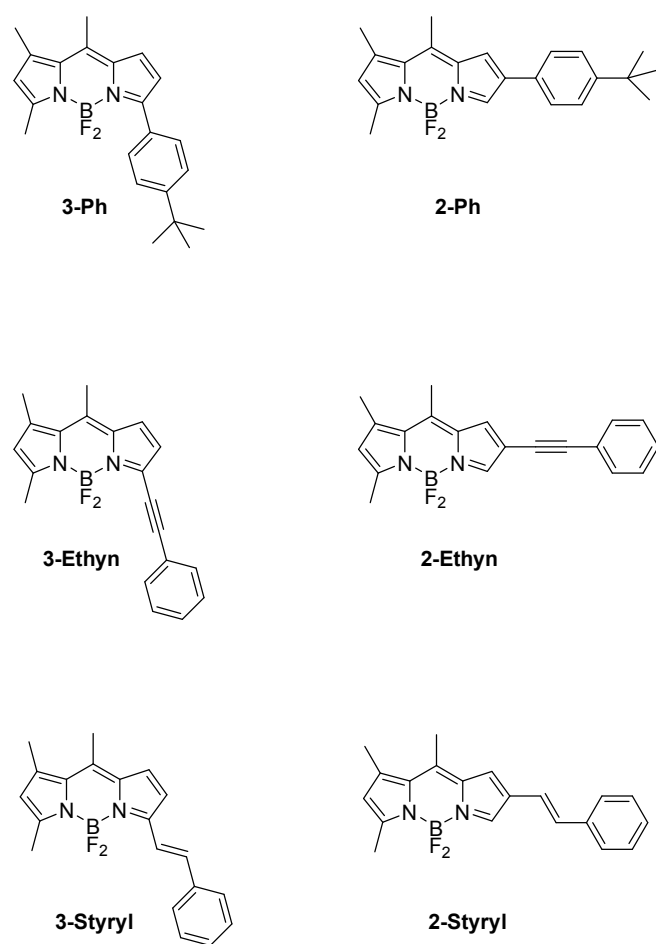<smiles></smiles>

2-Ph<smiles></smiles>

8-Ethyn<smiles>CPn1cccc1/C=C/c1ccccc1</smiles>

8-Styryl

Chart 2. Chemical structures of the BODIPY derivatives studied in this work. 


\section{Results and Discussion}

\section{Synthesis reactions.}

Nine BODIPY derivatives (Chart 2) having three types of substituents, at either the 2-, 3- or 8-position, have been prepared for this study: phenyl derivatives (2-Ph, 3-Ph and 8-Ph), phenylethynyl derivatives (2-Ethyn, 3-Ethyn and 8-Ethyn) and styryl derivatives (2-Styryl, 3-Styryl and 8-Styryl). The synthesis of 2-Ph, 3-Ph, 2-Ethyn and 3-Ethyn was carried out by following our previously reported procedure, ${ }^{37}$ whereas the synthesis of 8-Ph was performed as described by Kee et al. ${ }^{32}$ Also 8-Ethyn ${ }^{26}$ and 3-Styryl ${ }^{35}$ were synthesized prepared according to our protocols. Novel synthetic procedures for BODIPY derivatives 2-Styryl and 8-Styryl are described next.

2-Styryl [4,4-difluoro-5,7,8-trimethyl-2-(E)-styryl-4-bora-3a,4a-diaza-s-indacene] was prepared as follows (Scheme 1): To a stirred solution of BODIPY 1 (117 mg, $0.33 \mathrm{mmol}$, prepared as in reference ${ }^{37}$ ) in toluene $(5 \mathrm{~mL})$ at room temperature, $(E)$-styrylboronic acid $(64 \mathrm{mg}, 0.43 \mathrm{mmol}$ ) and tetrakis(triphenylphosphine) palladium (4 $\mathrm{mg}, 3.4 \mu \mathrm{mol}$ ) were added, followed by the addition of $1.5 \mathrm{~mL}$ of $\mathrm{Na}_{2} \mathrm{CO}_{3} 1 \mathrm{M}(\mathrm{aq})$. The solution was heated to reflux and after $3 \mathrm{~h}$ the reaction mixture was poured in $\mathrm{Et}_{2} \mathrm{O}(300 \mathrm{~mL})$ and dried over magnesium sulfate. Compound 2-Styryl ( $24 \mathrm{mg}, 0.072 \mathrm{mmol}, 22 \%$ yield) was obtained as a dark purple solid powder after purification by silica gel column chromatography [petroleum ether/dichloromethane, 2:1-1:1 (v/v)]. M.p. $219{ }^{\circ} \mathrm{C} . ~ N M R$ spectra (Figures S1 and S2 in the Electronic Supplementary Information, ESI): ${ }^{1} \mathrm{H} \mathrm{NMR}\left(600 \mathrm{MHz}, \mathrm{CDCl}_{3}\right) \delta 7.77(\mathrm{~s}$, $1 \mathrm{H}), 7.45(\mathrm{~d}, J=7.4 \mathrm{~Hz}, 2 \mathrm{H}), 7.34(\mathrm{t}, J=7.4 \mathrm{~Hz}, 2 \mathrm{H}), 7.23(\mathrm{t}, J=7.4 \mathrm{~Hz}, 1 \mathrm{H}), 7.16(\mathrm{~s}, 1 \mathrm{H}), 6.98(\mathrm{~d}, J=16.3 \mathrm{~Hz}, 1 \mathrm{H})$, $6.91(\mathrm{~d}, J=16.3 \mathrm{~Hz}, 1 \mathrm{H}), 6.17(\mathrm{~s}, 1 \mathrm{H}), 2.58(\mathrm{~s}, 3 \mathrm{H}), 2.57(\mathrm{~s}, 3 \mathrm{H}), 2.43(\mathrm{~s}, 3 \mathrm{H}) \mathrm{ppm} .{ }^{13} \mathrm{C} \mathrm{NMR}\left(75 \mathrm{MHz}, \mathrm{CDCl}_{3}\right) \delta 160.5$, 145.6, 141.5, 137.7, 137.1, 134.9, 134.6, 129.5, 128.8, 127.6, 127.4, 126.2, 123.1, 120.6, 119.4, 77.2, 17.1, 16.6, $15.1 \mathrm{ppm}$. LRMS (EI): 336, 316 (M-F).

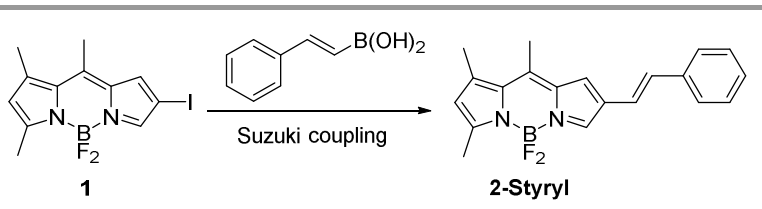

Scheme 1. Schematic representation of the synthesis of 2-Styryl.

8-Styryl [4,4-difluoro-8-(E)-styryl-4-bora-3a,4a-diaza-s-indacene] was prepared as follows (Scheme 2): To a solution of BODIPY 2 ( $310 \mathrm{mg}, 1.5 \mathrm{mmol}$, prepared as in reference $\left.{ }^{38}\right)$ in toluene $(15 \mathrm{~mL})$ under continuous stirring at $110{ }^{\circ} \mathrm{C}$, benzaldehyde $3(200 \mu \mathrm{L}, 1.97 \mathrm{mmol})$, acetic acid $(1.2 \mathrm{~mL}, 20.9 \mathrm{mmol})$ and piperidine $(1.0 \mathrm{~mL}, 10.1$ $\mathrm{mmol}$ ) were added. Instantaneous formation of a red-colored compound was observed. After 5 min, the solution was cooled to room temperature and the solvent was evaporated. After silica column purification [petroleum ether/dichloromethane, 1:9 (v/v)], 8-Styryl (127 mg, $0.43 \mathrm{mmol}, 29 \%$ yield) was obtained as a dark solid. M.p. 140 ${ }^{\circ} \mathrm{C}$. NMR spectra (Figures S3 and S4): ${ }^{1} \mathrm{H}$ NMR $\left(600 \mathrm{MHz}, \mathrm{CDCl}_{3}\right) \delta 7.89(\mathrm{~s}, 2 \mathrm{H}), 7.62(\mathrm{~d}, J=6.6 \mathrm{~Hz}, 2 \mathrm{H}), 7.52(\mathrm{~d}, J=$ $15.9 \mathrm{~Hz}, 1 \mathrm{H}), 7.48-7.42(\mathrm{~m}, 4 \mathrm{H}), 7.37(\mathrm{~s}, 2 \mathrm{H}), 6.56(\mathrm{~s}, 2 \mathrm{H}) \mathrm{ppm} .{ }^{13} \mathrm{C} \mathrm{NMR}\left(75 \mathrm{MHz}, \mathrm{CDCl}_{3}\right) \delta 144.71,143.75$, $143.02,135.53,133.83,130.54,129.17,128.28,127.98,121.13,117.89$ ppm. HRMS (EI) calculated for $C_{17} \mathrm{H}_{13} \mathrm{BF}_{2} \mathrm{~N}_{2}$ 294.1140, found 294.1143. LRMS (EI): 294, 273 [M - F].

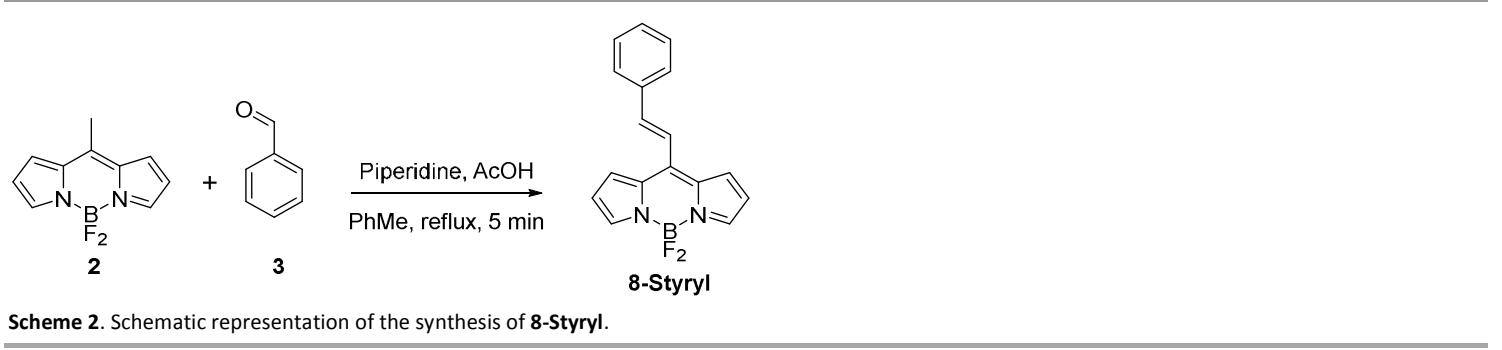


All BODIPY dyes synthesized for this study are solid powders with a strongly colored metallic shine and form intensely colored solutions. When irradiated in solution, a generally bright fluorescence can be observed. In the following sections, we describe the spectroscopic and photophysical features of these dyes, including solvent effects.

\section{Spectroscopic and photophysical properties.}

The UV-vis absorption and fluorescence emission spectra of the nine compounds dissolved in 18 solvents (see Table S1 in the ESI) have been measured. The dyes exhibit typical BODIPY-like absorption spectra with a narrow band due to the $S_{1} \leftarrow S_{0}$ transition and a shoulder at lower wavelengths. A blue-shifted, weak $S_{2} \leftarrow S_{0}$ transition band is also detectable in some of the spectra.

Among the phenyl-substituted BODIPY dyes (2-Ph, 3-Ph and 8-Ph), some differences in absorption behavior are observed. The presence of the $p$-tert-butylphenyl moiety shifts the absorption maximum $\lambda_{\text {abs }}(\max )$ from $516-$ $530 \mathrm{~nm}$ when this group is at the 2-position (2-Ph) to $513-527 \mathrm{~nm}$ when it is at the 3-position (3-Ph). In both cases, $\lambda_{\text {abs }}(\max )$ is more red-shifted in the more polarizable solvents toluene and chlorobenzene. In contrast, the values of $\lambda_{\text {abs }}(\max )$ of 8-Ph (with a phenyl substituent at the meso-position) are blue-shifted in relation to those of 2-Ph and 3-Ph and are close to those of unsubstituted boron dipyrromethene, ${ }^{3,22-24}$ ranging from $489 \mathrm{~nm}$ in acetonitrile to $497 \mathrm{~nm}$ in toluene and chlorobenzene: the solvent dependence correlating with the refractive index. This absorption energy range is in good agreement with that of other BODIPYs substituted at the mesoposition with a weak electron acceptor or donor. ${ }^{33,39}$ One should also note that the absorption spectrum of 8-Ph is similar to BODIPY dyes substituted by a mesityl or 0 -tolyl moiety in 8-position. This is due to the large dihedral angle $\left(60^{\circ}\right)$ between the BODIPY and phenyl moiety found for 8-Ph by X-ray diffraction, ${ }^{32}$ which reduces the delocalization of the electron cloud of the BODIPY moiety over the phenyl group. ${ }^{27}$

For the phenylethynylBODIPYs (2-Ethyn, 3-Ethyn and 8-Ethyn), the absorption spectra exhibit also the characteristic features of typical BODIPYs. 2-Ethyn possesses an absorption maximum between 503 and $525 \mathrm{~nm}$, whereas the $\lambda_{\text {abs }}$ (max) of 3-Ethyn varies between 525 and $545 \mathrm{~nm}$ (Figure 1A). For both dyes, the lowest $\lambda_{\text {abs }}(\max )$ value is found in acetonitrile and the largest in cyclohexane. Remarkably, the effect of the substitution position ( 2 vs. 3) on $\lambda_{\text {abs }}(\max )$ is much larger for the phenylethynyl moiety than for the phenyl group and, moreover, is opposite: moving the p-tert-butylphenyl substituent from the 2-(2-Ph) to the 3-position (3-Ph) causes a $3 \mathrm{~nm}$ blue shift of $\lambda_{\text {abs }}(\max )$, whereas the analogous change from 2-Ethyn to 3-Ethyn results in a ca. $20 \mathrm{~nm}$ red shift of $\lambda_{\text {abs }}(\max )$. The previously reported 8-Ethyn ${ }^{27}$ is bathochromically shifted with respect to 2-Ethyn and 3-Ethyn, with $\lambda_{\text {abs }}$ (max) ranging from 537 to $547 \mathrm{~mm}$ (see Table S2) parallel with an increasing refractive index. As the HOMO of the BODIPY core has a node in the 8-position, these data suggest that the 8-phenylethynyl moiety acts as an electron acceptor stabilizing the LUMO. This rationale also helps to account for the difference between 2Ethyn and 3-Ethyn. The resonance forms of BODIPY suggest that, as in the 8-position, the coefficient of the HOMO in the 3-postion is smaller than in the 2-position, the opposite being the case for those of the LUMO. Hence if the phenylethynyl moiety stabilizes the LUMO rather than destabilizing the HOMO, its effect and hence the red shift vs. unsubstituted BODIPY, will be most outspoken for 3-Ethyn and 8-Ethyn. Strikingly, the $\lambda_{\text {abs }}(\max )$ values of the 8-Ph are blue shifted with respect to those of 3-Ph and 2-Ph.

Styryl-substituted BODIPYs (2-Styryl, 3-Styryl and 8-Styryl) exhibit different absorption properties. 3-Styryl displays a main, narrow $\mathrm{S}_{1} \leftarrow \mathrm{S}_{0}$ transition band (Figure $2 \mathrm{~A}$ ) similar to other 3-substituted boron dipyrromethenes. ${ }^{35,37}$ The $\lambda_{\text {abs }}$ (max) values range from 549 to $561 \mathrm{~nm}$, with a typical red shift from acetonitrile to chlorobenzene. The extended conjugation provided by the styryl functional group causes an extra bathochromic shift of around $20 \mathrm{~nm}$ with respect to 3-Ethyn, and ca. $30 \mathrm{~nm}$ with respect to 3-Ph. In contrast, 2-Styryl and 8Styryl exhibit a clear dual-band absorption and emission behavior (Figures S5). The relative abundance of each band varies with the solvent, and the absorption and the excitation spectra do not match. Multi-exponential fluorescence decay traces were also found for both dyes. Likewise, both BODIPY dyes undergo changes in the relative absorption of each band with time (Figure S6) and completely discolor after $180 \mathrm{~min}$ in solvents such as THF and cyclohexanone, even when the solution is kept in the dark. This effect is especially observed for 2-Styryl, but can also be detected for 8-Styryl. This is indicative of (photo-)instability of the dyes. Because of this (photo)instability, no further experiments were performed with 2-Styryl and 8-Styryl. 

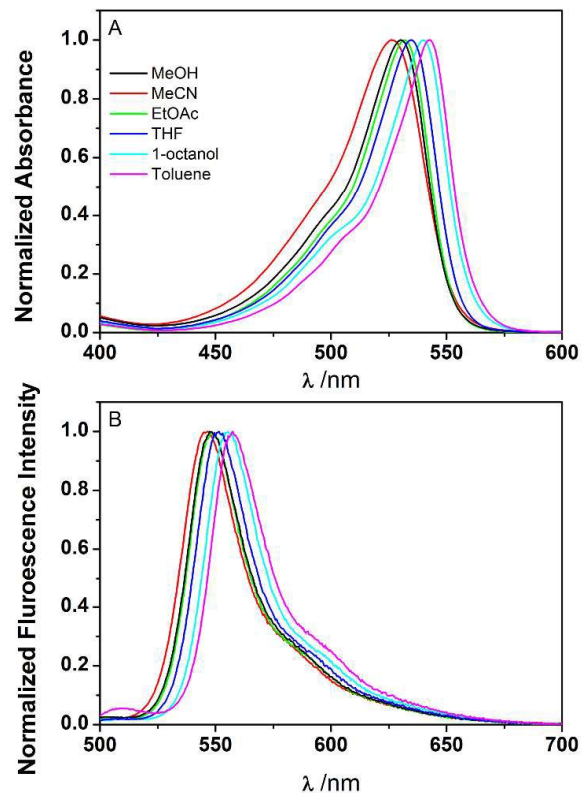

Figure 1. (A) Normalized absorption spectra of 3-Ethyn in a selection of solvents. (B) Corresponding normalized fluorescence emission spectra upon excitation at $488 \mathrm{~nm}$.
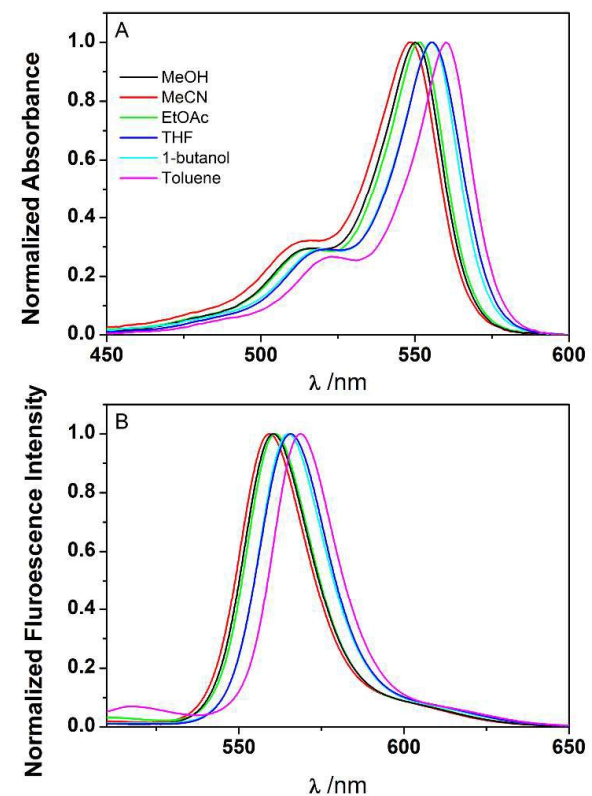

Figure 2. (A) Normalized absorption spectra of 3-Styryl in a selection of solvents. (B) Corresponding normalized fluorescence emission spectra upon excitation at $510 \mathrm{~nm}$.

The most interesting spectroscopic features are related to the fluorescence emission of the BODIPY derivatives. Herein, we compare the maxima of the emission spectra $\left[\lambda_{e m}(\max )\right]$, Stokes shifts $(\Delta \bar{v})$, fluorescence quantum yields $(\Phi)$ and lifetimes $(\tau)$, and other fluorescence-related properties of the dyes studied.

A comparison of the phenyl-substituted BODIPY dyes (2-Ph, 3-Ph and 8-Ph) already highlights very remarkable differences (Tables 1 and 2). 3-Ph and 8-Ph display the characteristic emission features of boron dipyrromethenes: (a) a mirror image-shaped, narrow emission band ( $f w h m_{e m}$ averaged over all the solvents tested equals $1060 \pm 50 \mathrm{~cm}^{-1}$ and $1390 \pm 110 \mathrm{~cm}^{-1}$ for 3-Ph and 8-Ph, respectively); (b) a small Stokes shift $\Delta \bar{v}$ [in 
the 859-1111 cm $\mathrm{cm}^{-1}$ range for 3-Ph (average $\Delta \bar{V}=990 \pm 67 \mathrm{~cm}^{-1}$ ) and in the $633-856 \mathrm{~cm}^{-1}$ range for 8-Ph (average $\left.\Delta \bar{v}=726 \pm 62 \mathrm{~cm}^{-1}\right)$ ]; (c) emission maxima $\lambda_{\mathrm{em}}(\max )$ that are red-shifted in the more polarizable solvents $\left[\lambda_{\mathrm{em}}(\max )\right.$ moves from $544 \mathrm{~nm}$ in acetonitrile to $554 \mathrm{~nm}$ in chlorobenzene and toluene for 3-Ph, whereas for 8-Ph $\lambda_{\mathrm{em}}(\max )$ varies from $507 \mathrm{~nm}$ in methanol to $517 \mathrm{~nm}$ in toluene and $518 \mathrm{~nm}$ in cyclohexane]. The fwhm $\mathrm{em}_{\text {results }}$ are intermediate between those of 8-methylBOBIPY ( $f w h m_{e m}$ around $\left.950 \mathrm{~cm}^{-1}\right)^{19}$ and those of meso-halogenated BODIPYs ( $f w h m_{e m}$ around $1400 \mathrm{~cm}^{-1}$ ), as is the trend in the emission maxima $\lambda_{\mathrm{em}}$ (max) with the different solvents. However, the Stokes shifts $\Delta \bar{v}$ are larger than those reported for meso-alkylated and meso-halogenated BODIPY dyes, which are in the $400 \mathrm{~cm}^{-1}$ range. ${ }^{17,33,40}$ For instance, meso- $p$-methylphenyl-3,5-dimethylBODIPY and meso$p$-methylphenyl-1,3,5,7-tetramethylBODIPYs exhibit $\Delta \bar{v}$ values between 513 and $627 \mathrm{~cm}^{-1},{ }^{34}$ and between 447 and $560 \mathrm{~cm}^{-1}$ for meso-phenyl-3,5-dimethylBODIPY. ${ }^{33}$ Concerning the solvent dependence of these spectroscopic parameters, one can observe that while for 3-Ph $\Delta \bar{v}, \mathrm{fwhm}_{\mathrm{abs}}$ and fwhm $\mathrm{fm}_{\mathrm{encrease}}$ more or less parallel with the dielectric constant $\varepsilon$ of the solvent, this relation is quite erratic for $\Delta \bar{v}$ and fwhmem of 8-Ph.

In order to better understand the differences between different of BODIPYs, we also analyzed the relation between $\Delta \bar{v}$ and fwhm $\mathrm{em}_{\mathrm{em}}$ or fwhm $\mathrm{fbs}_{\mathrm{ab}}$ more quantitatively. If only low frequency molecular vibrations $\left(h v_{\text {vib }}<k \mathrm{~T}\right)$ contribute to $\Delta \bar{v}$ and fwhm $\mathrm{em}_{\mathrm{e}}$ or fwhm $\mathrm{abs}$, the relation between both properties is given by eqn (1): ${ }^{41-43}$

$(\mathrm{fwhm})^{2}=16(\ln 2) E_{R} k T$

where $E_{R}$ is the excess energy with which a vertical transition from the minimum of the ground state reaches the excited state potential energy surface (PES) upon absorption of a photon (and analogously for emission). Hence the Stokes shift $\Delta \bar{v}$ is $2 E_{R}$. For $T=290 \mathrm{~K}$, eqn (1) can be expressed as: $\Delta \bar{v}=8.9514 \times 10^{-4}(\mathrm{fwhm})^{2}$ (in $\mathrm{cm}^{-1}$ ). For 3$\mathrm{Ph}$ and 8-Ph the average fwhm $\mathrm{em}_{\mathrm{em}}$ is respectively $1060 \pm 50 \mathrm{~cm}^{-1}$ and $1390 \pm 110 \mathrm{~cm}^{-1}$, which yields a respective average Stokes shift $\Delta \bar{v}$ of 1010 and $1730 \mathrm{~cm}^{-1}$ using eqn (1). For 3-Ph this matches the average experimental $\Delta$ $\bar{v}$ value of $990 \mathrm{~cm}^{-1}$. However, for 8-Ph the average $\Delta \bar{v}$ value calculated according to eqn (1) is more than twice as large as the experimental value, which is only $726 \mathrm{~cm}^{-1}$. When instead of the average values of fwhm $\mathrm{em}_{\mathrm{em}}$ the average values of fwhm $\mathrm{abs}_{\text {se }}$ ased, one finds $2320 \mathrm{~cm}^{-1}$ and $1030 \mathrm{~cm}^{-1}$ for the average calculated $\Delta \bar{V}$ of 3-Ph and 8-Ph, respectively. Now the average value of the experimental $\Delta \overline{\mathbf{V}}$ of $\mathbf{3}-\mathbf{P h}$ is overestimated by more than a factor of 2, whereas the agreement with that of $\mathbf{8}-\mathbf{P h}$ is marginal. While for $\mathbf{3}-\mathbf{P h}$ the fwhm $_{\text {abs }}$ is significantly broader than $\mathrm{fwhm}_{\mathrm{em}}\left(1610 \mathrm{vs} .1060 \mathrm{~cm}^{-1}\right)$, the reverse trend is observed for 8-Ph $\left(1080 \mathrm{vs} .1390 \mathrm{~cm}^{-1}\right)$. This would suggest that for 3-Ph the PES is steeper in the excited state than in the ground state, while for 8-Ph the opposite is suggested. The steep PES for the ground state could be due to steric hindrance. In contrast to what was observed earlier for molecules with a strongly dipolar excited state, ${ }^{43}$ the values of the Stokes shift estimated from the $f_{w h m_{a b s}}$ and fwhm $\mathrm{em}_{\mathrm{em}}$ are overestimated and the deviation becomes stronger for broader bands. Especially when the bands of the BODIPY derivatives get broader, fwhm $\mathrm{abs}_{\mathrm{a}}$ and $\mathrm{fwhm}_{\mathrm{em}}$ are no longer uniquely determined by low frequency (torsional) vibrations but also envelope the $0-1$ high frequency vibronic band. However, the absorption and emission maxima whose position determines the Stokes shift always corresponds with the $0-0$ vibronic band of the high frequency vibration for the compounds studied here. The emission maximum of 2-Ph varies with the solvent, ranging from $566 \mathrm{~nm}$ in cyclohexane to $583 \mathrm{~nm}$ in cyclohexanone and acetone. The spectral emission features of 2-Ph differ significantly from those of 3-Ph and 8-Ph. 2-Ph exhibits a much broader emission band (average $\mathrm{fwhm}_{\mathrm{em}}=2050 \pm 240 \mathrm{~cm}^{-1}$ ) than 3-Ph and 8-Ph do, as well as a larger Stokes shift $\Delta \bar{V}$ (average $\Delta \bar{V}=1799 \pm 243 \mathrm{~cm}^{-1}$ ). Moreover, fwhmabs of 2-Ph $\left(2200 \pm 50 \mathrm{~cm}^{-1}\right.$ ) is similar to $\mathrm{fwhm}_{\mathrm{em}}$ and hence quite broader than the average $\mathrm{fwhm}_{\mathrm{abs}}$ of $\mathbf{3 - P h}\left(1610 \mathrm{~cm}^{-1}\right)$ and 8-Ph $\left(1080 \mathrm{~cm}^{-1}\right)$. As observed for 8-Ph, the average $\Delta \bar{v}$ of 2-Ph, as calculated from fwhm $\mathrm{fm}_{\mathrm{m}}$ using eqn (1), is much larger than the experimental value $\left(3750 \mathrm{~cm}^{-1}\right.$ vs. $\left.1799 \mathrm{~cm}^{-1}\right)$. When the values of fwhmabs are used to calculate the average Stokes shift of 2-Ph an even larger value of $4340 \mathrm{~cm}^{-1}$ is found. However, in contrast to what was observed for 8$\mathrm{Ph}$, but in accordance to what was found for 3-Ph, fwhm $\mathrm{fm}_{\mathrm{em}}, \mathrm{fwhm}_{\mathrm{abs}}$ and $\Delta \overline{\mathrm{V}}$ of 2-Ph increase roughly parallel with the dielectric constant $\varepsilon$ of the solvent. 3-Ph exhibits large $\Phi$ values, from 0.81 to 1.00 , which are in good agreement with previously reported ones, ${ }^{35,37}$ except for 3-Ph in toluene that shows a slightly larger $\Phi$ in this work. Regarding the rate constants of radiative $\left(k_{\mathrm{f}}\right)$ and nonradiative $\left(k_{\mathrm{nr}}\right) \mathrm{S}_{1}$ deactivation, 3-Ph shows an increase of $k_{\mathrm{f}}$ with solvent refractive index $n$, from $1.6 \times 10^{8} \mathrm{~s}^{-1}$ in methanol to $2.2 \times 10^{8} \mathrm{~s}^{-1}$ in toluene, whereas $k_{\mathrm{nr}}$ ranges from negligible values in diethyl ether and 1,4-dioxane to $0.4 \times 10^{8} \mathrm{~s}^{-1}$ in methanol. 2-Ph shows remarkable differences in the $\Phi$ values as a function of the solvent used, ranging from 0.359 to 0.72 . For $\mathbf{2 - P h}$, there is no clear trend in the solvent dependence of $k_{\mathrm{f}}$ with an average value of $(1.0 \pm 0.1) \times 10^{8} \mathrm{~s}^{-1}$. For $k_{\mathrm{nr}}$ an increase with the dielectric constant $\varepsilon$ of the solvent can be observed. The average $k_{\mathrm{nr}}$ value of 2-Ph amounts to $(0.9 \pm 0.2) \times 10^{8}$ $\mathrm{s}^{-1}$. The larger values of $k_{\mathrm{nr}}$ observed for 2-Ph compared to 3-Ph, correlate with its larger values of fwhm $\mathrm{em}_{\mathrm{em}}$ and $\bar{v}$, suggesting a larger displacement of the PES of the ground state and the excited state. This larger displacement leads to a better Franck-Condon factor between the zeroth vibrational level of the excited state and an isoenergetic vibrational level of the ground state. ${ }^{33}$ In contrast to 2-Ph and 3-Ph, substitution at the meso-position in 
8-Ph diminishes drastically the $\Phi$ values (similar to the values observed earlier in toluene), ${ }^{32}$ so that 8-Ph is a much less bright fluorescent dye than its 2- and 3-phenyl-substituted equivalents. The average $k_{\mathrm{f}}$ value of 8-Ph is $(2.8 \pm 0.9) \times 10^{8} \mathrm{~s}^{-1}$, in the same range as for the 2 - and 3 -substituted analogues. However, $k_{\mathrm{nr}}$ is much larger, with an average value of $(33 \pm 12) \times 10^{8} \mathrm{~s}^{-1}$, due to a different equilibrium position along the rotational coordinate in the ground and excited state. ${ }^{32-33}$ This makes the fluorescence lifetime $\tau$ much shorter for 8-Ph than for 2-Ph and 3-Ph (Fig. S7). For $k_{\mathrm{f}}$ of 8-Ph there is no trend in the solvent dependence. The highest $k_{\mathrm{nr}}$ values of 8-Ph are found for the highly polar, nonpolarizable solvents methanol, acetonitrile and acetone while the lowest $k_{\mathrm{nr}}$ values are observed for the nonpolar, highly polarizable solvents chloroform, toluene and chlorobenzene. There is however no clear relation with solvent polarity of polarizability. A previous publication suggested that this could be due to the effect of the environment viscosity. ${ }^{32}$ Tables 1 and 2 compile the spectroscopic and photophysical data of 2 $\mathbf{P h}, \mathbf{3 - P h}$ and 8-Ph as a function of solvent.

Table 1. Spectroscopic and photophysical data of 3-Ph and 2-Ph as a function of solvent. The solvents are numbered according to increasing refractive index $n$ as in Table S1.

\begin{tabular}{|c|c|c|c|c|c|c|c|c|c|c|c|}
\hline \multirow[t]{2}{*}{ Product } & & \multirow[t]{2}{*}{ Solvent } & \multirow{2}{*}{$\begin{array}{c}\lambda_{\text {abs }} \\
(\max ) \\
{[\mathrm{nm}]}\end{array}$} & \multirow{2}{*}{$\begin{array}{c}\lambda_{\mathrm{em}} \\
(\mathrm{max}) \\
{[\mathrm{nm}]}\end{array}$} & \multirow{2}{*}{$\begin{array}{c}\Delta \bar{v} \\
{\left[\mathrm{~cm}^{-1}\right]}\end{array}$} & \multirow{2}{*}{$\begin{array}{c}\text { fwhm }{ }_{\text {abs }} \\
{\left[\mathrm{cm}^{-1}\right]}\end{array}$} & \multirow{2}{*}{$\begin{array}{c}\text { fwhm } \\
{\left[\mathrm{cm}^{-1}\right]}\end{array}$} & \multirow[t]{2}{*}{$\Phi^{a}$} & \multirow{2}{*}{$\begin{array}{c}\tau^{b} \\
{[\mathrm{~ns}]}\end{array}$} & \multirow{2}{*}{$\begin{array}{c}k_{f}^{c} \\
{\left[10^{8} \mathrm{~s}^{-1}\right]}\end{array}$} & \multirow{2}{*}{$\begin{array}{c}k_{\mathrm{nr}}{ }^{c} \\
{\left[10^{8} \mathrm{~s}^{-1}\right]}\end{array}$} \\
\hline & & & & & & & & & & & \\
\hline \multirow[t]{18}{*}{ 3-Ph } & 1 & $\mathrm{CH}_{3} \mathrm{OH}$ & 517 & 547 & 1061 & 1680 & 1110 & $0.81 \pm 0.01$ & 5.13 & $1.58 \pm 0.02$ & $0.37 \pm 0.02$ \\
\hline & 2 & $\mathrm{CH}_{3} \mathrm{CN}$ & 513 & 544 & 1111 & 1700 & 1170 & $0.895 \pm 0.001$ & 5.08 & $1.76 \pm 0.01$ & $0.21 \pm 0.01$ \\
\hline & 3 & $\left(\mathrm{C}_{2} \mathrm{H}_{5}\right)_{2} \mathrm{O}$ & 522 & 549 & 942 & 1530 & 1040 & $1.00 \pm 0.02$ & 5.11 & $1.96 \pm 0.04$ & $0.00 \pm 0.04$ \\
\hline & 4 & Acetone & 518 & 547 & 1023 & 1630 & 1110 & $0.895 \pm 0.005$ & 5.09 & $1.76 \pm 0.01$ & $0.21 \pm 0.01$ \\
\hline & 5 & $\mathrm{EtOAc}^{d}$ & 519 & 547 & 986 & 1630 & 1090 & $0.86 \pm 0.02$ & 4.89 & $1.76 \pm 0.04$ & $0.29 \pm 0.04$ \\
\hline & 6 & 2-Propanol & 520 & 550 & 1049 & 1620 & 1080 & $0.91 \pm 0.01$ & 4.96 & $1.84 \pm 0.02$ & $0.18 \pm 0.02$ \\
\hline & 7 & $\mathrm{PrCN}^{d}$ & 518 & 548 & 1057 & 1670 & 1090 & $0.99 \pm 0.03$ & 4.90 & $2.02 \pm 0.06$ & $0.02 \pm 0.06$ \\
\hline & 8 & $\mathrm{Bu}_{2} \mathrm{O}^{d}$ & 525 & 551 & 899 & 1520 & 1010 & $0.96 \pm 0.08$ & 4.84 & $1.98 \pm 0.17$ & $0.08 \pm 0.17$ \\
\hline & 9 & $\mathrm{THF}^{d}$ & 522 & 551 & 1008 & 1570 & 1060 & $0.877 \pm 0.009$ & 4.71 & $1.86 \pm 0.02$ & $0.26 \pm 0.02$ \\
\hline & 10 & 1-Pentanol & 523 & 552 & 1005 & 1600 & 1040 & $0.899 \pm 0.007$ & 4.81 & $1.87 \pm 0.02$ & $0.21 \pm 0.02$ \\
\hline & 11 & 1,4-Dioxane & 521 & 550 & 1012 & 1650 & 1060 & $1.00 \pm 0.05$ & 4.65 & $2.15 \pm 0.11$ & $0.00 \pm 0.11$ \\
\hline & 12 & $\mathrm{CH}_{2} \mathrm{Cl}_{2}$ & 521 & 551 & 1045 & 1660 & 1100 & $0.87 \pm 0.01$ & 4.99 & $1.74 \pm 0.02$ & $0.26 \pm 0.02$ \\
\hline & 13 & $\mathrm{c}-\mathrm{C}_{6} \mathrm{H}_{12}{ }^{d}$ & 527 & 552 & 859 & 1470 & 960 & $0.99 \pm 0.07$ & 4.68 & $2.12 \pm 0.15$ & $0.02 \pm 0.15$ \\
\hline & 14 & 1-Octanol & 525 & 553 & 964 & 1550 & 1020 & $0.92 \pm 0.04$ & 4.76 & $1.93 \pm 0.08$ & $0.17 \pm 0.08$ \\
\hline & 15 & $\mathrm{CHCl}_{3}$ & 524 & 553 & 1001 & 1630 & 1050 & $0.94 \pm 0.09$ & 4.99 & $1.88 \pm 0.18$ & $0.12 \pm 0.18$ \\
\hline & 16 & $\mathrm{c}-\mathrm{C}_{6} \mathrm{H}_{10} \mathrm{O}^{d}$ & 522 & 551 & 1008 & 1640 & 1070 & $0.99 \pm 0.06$ & 4.54 & $2.18 \pm 0.13$ & $0.02 \pm 0.13$ \\
\hline & 17 & Toluene & 527 & 554 & 925 & 1580 & 1000 & $0.97 \pm 0.02$ & 4.39 & $2.21 \pm 0.05$ & $0.07 \pm 0.05$ \\
\hline & 18 & $\mathrm{PhCl}^{d}$ & 527 & 554 & 925 & 1610 & 1030 & $0.94 \pm 0.09$ & 4.36 & $2.16 \pm 0.21$ & $0.14 \pm 0.21$ \\
\hline \multirow[t]{18}{*}{ 2-Ph } & 1 & $\mathrm{CH}_{3} \mathrm{OH}$ & 519 & 582 & 2086 & 2300 & 2320 & $0.359 \pm 0.005$ & 4.23 & $0.85 \pm 0.01$ & $1.52 \pm 0.01$ \\
\hline & 2 & $\mathrm{CH}_{3} \mathrm{CN}$ & 516 & 581 & 2168 & 2260 & 2440 & $0.442 \pm 0.005$ & 4.89 & $0.90 \pm 0.01$ & $1.14 \pm 0.01$ \\
\hline & 3 & $\left(\mathrm{C}_{2} \mathrm{H}_{5}\right)_{2} \mathrm{O}$ & 525 & 573 & 1596 & 2190 & 1960 & $0.58 \pm 0.02$ & 5.98 & $0.97 \pm 0.03$ & $0.70 \pm 0.03$ \\
\hline & 4 & Acetone & 519 & 583 & 2115 & 2270 & 2310 & $0.47 \pm 0.01$ & 5.11 & $0.92 \pm 0.02$ & $1.04 \pm 0.02$ \\
\hline & 5 & $\mathrm{EtOAc}^{d}$ & 521 & 576 & 1833 & 2250 & 2110 & $0.56 \pm 0.01$ & 5.47 & $1.02 \pm 0.02$ & $0.80 \pm 0.02$ \\
\hline & 6 & 2-Propanol & 522 & 581 & 1945 & 2240 & 2160 & $0.61 \pm 0.02$ & 5.08 & $1.20 \pm 0.04$ & $0.77 \pm 0.04$ \\
\hline & 7 & $\mathrm{PrCN}^{d}$ & 520 & 582 & 2049 & 2230 & 2280 & $0.36 \pm 0.02$ & 5.18 & $0.69 \pm 0.04$ & $1.24 \pm 0.04$ \\
\hline & 8 & $\mathrm{Bu}_{2} \mathrm{O}^{d}$ & 527 & 571 & 1462 & 2160 & 1770 & $0.58 \pm 0.06$ & 5.87 & $1.0 \pm 0.1$ & $0.7 \pm 0.1$ \\
\hline & 9 & $\mathrm{THF}^{d}$ & 525 & 581 & 1836 & 2190 & 2090 & $0.571 \pm 0.004$ & 5.34 & $1.07 \pm 0.01$ & $0.80 \pm 0.01$ \\
\hline & 10 & 1-Pentanol & 525 & 580 & 1806 & 2180 & 2050 & $0.61 \pm 0.01$ & 5.24 & $1.16 \pm 0.02$ & $0.74 \pm 0.02$ \\
\hline & 11 & 1,4-Dioxane & 524 & 575 & 1693 & 2140 & 1990 & $0.57 \pm 0.02$ & 5.76 & $0.99 \pm 0.04$ & $0.75 \pm 0.04$ \\
\hline & 12 & $\mathrm{CH}_{2} \mathrm{Cl}_{2}$ & 523 & 581 & 1909 & 2160 & 2150 & $0.57 \pm 0.02$ & 5.53 & $1.03 \pm 0.04$ & $0.78 \pm 0.04$ \\
\hline & 13 & $\mathrm{C}-\mathrm{C}_{6} \mathrm{H}_{12}{ }^{d}$ & 528 & 566 & 1272 & 2180 & 1500 & $0.72 \pm 0.05$ & 5.80 & $1.24 \pm 0.09$ & $0.48 \pm 0.09$ \\
\hline & 14 & 1-Octanol & 527 & 579 & 1704 & 2200 & 2030 & $0.50 \pm 0.02$ & 5.56 & $0.90 \pm 0.04$ & $0.90 \pm 0.04$ \\
\hline & 15 & $\mathrm{CHCl}_{3}$ & 526 & 582 & 1829 & 2140 & 2000 & $0.52 \pm 0.04$ & 5.75 & $0.90 \pm 0.07$ & $0.83 \pm 0.07$ \\
\hline & 16 & $\mathrm{C}-\mathrm{C}_{6} \mathrm{H}_{10} \mathrm{O}^{d}$ & 523 & 583 & 1968 & 2240 & 2180 & $0.43 \pm 0.02$ & 5.19 & $0.83 \pm 0.04$ & $1.10 \pm 0.04$ \\
\hline & 17 & Toluene & 530 & 575 & 1477 & 2110 & 1800 & $0.63 \pm 0.02$ & 5.50 & $1.15 \pm 0.04$ & $0.67 \pm 0.04$ \\
\hline & 18 & $\mathrm{PhCl}^{d}$ & 529 & 582 & 1721 & 2150 & 1960 & $0.53 \pm 0.06$ & 5.40 & $1.0 \pm 0.1$ & $0.9 \pm 0.1$ \\
\hline
\end{tabular}

${ }^{a}$ Fluorescence quantum yield \pm one standard uncertainty. $\Phi$ determined $v$ s. rhodamine $6 \mathrm{G}$ in water $\left(\Phi_{\mathrm{r}}=0.76\right)$ as a reference.

${ }^{b}$ Fluorescence lifetimes obtained with $\lambda_{\mathrm{ex}}=488 \mathrm{~nm}$, and $\lambda_{\mathrm{em}}(3-\mathrm{Ph})=560,565,570 \mathrm{~nm}$ or $\lambda_{\mathrm{em}}(2-\mathrm{Ph})=560,570,580 \mathrm{~nm}$. The standard errors are obtained from the diagonal elements of the covariance matrix available from the global analysis fit of decay traces recorded at three emission wavelengths $\lambda_{\text {em }}$ and are between 6 and 10 ps for 3-Ph and between 7 and 17 ps for 2-Ph

${ }^{c}$ The propagated errors are calculated using the uncertainty (standard deviation) of $\Phi$ and the standard error of $\tau$. 
${ }^{d}$ EtOAc $=$ ethyl acetate, $\mathrm{PrCN}=$ butanenitrile, $\mathrm{Bu}_{2} \mathrm{O}=$ dibutyl ether, $\mathrm{THF}=$ tetrahydrofuran, $\mathrm{c}-\mathrm{C}_{6} \mathrm{H}_{12}=\mathrm{cyclohexane}, \mathrm{c}-\mathrm{C}_{6} \mathrm{H}_{10} \mathrm{O}=\mathrm{cyclohexanone}, \mathrm{PhCl}=$ chlorobenzene.

\begin{tabular}{|c|c|c|c|c|c|c|c|c|c|c|c|}
\hline Product & & Solvent & $\begin{array}{c}\lambda_{\text {abs }}(\max ) \\
{[\mathrm{nm}]}\end{array}$ & $\begin{array}{c}\lambda_{\text {em }}(\max ) \\
{[\mathrm{nm}]}\end{array}$ & $\begin{array}{c}\Delta \bar{v} \\
{\left[\mathrm{~cm}^{-1}\right]}\end{array}$ & $\begin{array}{c}\text { fwhm }{ }_{\text {abs }} \\
{\left[\mathrm{cm}^{-1}\right]}\end{array}$ & $\begin{array}{c}\mathrm{fwhm} \\
{\left[\mathrm{cm}^{-1}\right]}\end{array}$ & $\Phi^{a}$ & $\begin{array}{c}\tau^{b} \\
{[\mathrm{ps}]}\end{array}$ & $\begin{array}{c}k_{\mathrm{f}}{ }^{c} \\
{\left[10^{8} \mathrm{~s}^{-1}\right]}\end{array}$ & $\begin{array}{c}k_{\mathrm{nr}}{ }^{c} \\
{\left[10^{8} \mathrm{~s}^{-1}\right]}\end{array}$ \\
\hline \multirow[t]{18}{*}{ 8-Ph } & 1 & $\mathrm{CH}_{3} \mathrm{OH}$ & 490 & 507 & 684 & 1180 & 1340 & $0.044 \pm 0.004$ & 189 & $2.3 \pm 0.2$ & $50.6 \pm 0.4$ \\
\hline & 2 & $\mathrm{CH}_{3} \mathrm{CN}$ & 489 & 510 & 842 & 1320 & 1420 & $0.041 \pm 0.004$ & 181 & $2.3 \pm 0.2$ & $53.0 \pm 0.4$ \\
\hline & 3 & $\left(\mathrm{C}_{2} \mathrm{H}_{5}\right)_{2} \mathrm{O}$ & 492 & 509 & 679 & 1000 & 1240 & $0.050 \pm 0.006$ & 235 & $2.1 \pm 0.3$ & $40.4 \pm 0.3$ \\
\hline & 4 & Acetone & 491 & 509 & 720 & 1180 & 1270 & $0.045 \pm 0.006$ & 180 & $2.5 \pm 0.3$ & $53.1 \pm 0.5$ \\
\hline & 5 & EtOAc $^{d}$ & 491 & 509 & 720 & 1090 & 1460 & $0.056 \pm 0.004$ & 220 & $2.5 \pm 0.2$ & $42.9 \pm 0.3$ \\
\hline & 6 & 2-Propanol & 492 & 511 & 756 & 1040 & 1340 & $0.082 \pm 0.004$ & 284 & $2.9 \pm 0.1$ & $32.3 \pm 0.2$ \\
\hline & 7 & $\operatorname{PrCN}^{d}$ & 491 & 511 & 797 & 1180 & 1460 & $0.06 \pm 0.02$ & 240 & $2.5 \pm 0.8$ & $39.2 \pm 0.9$ \\
\hline & 8 & $\mathrm{Bu}_{2} \mathrm{O}^{d}$ & 494 & 512 & 712 & 950 & 1440 & $0.074 \pm 0.004$ & 301 & $2.5 \pm 0.1$ & $30.8 \pm 0.2$ \\
\hline & 9 & $\mathrm{THF}^{d}$ & 493 & 511 & 715 & 1080 & 1250 & $0.065 \pm 0.007$ & 250 & $2.6 \pm 0.3$ & $37.4 \pm 0.3$ \\
\hline & 10 & 1-Pentanol & 494 & 511 & 673 & 1040 & 1430 & $0.12 \pm 0.01$ & 375 & $3.2 \pm 0.3$ & $23.5 \pm 0.3$ \\
\hline & 11 & 1,4-Dioxane & 494 & 511 & 673 & 1040 & 1360 & $0.12 \pm 0.01$ & 342 & $3.5 \pm 0.3$ & $25.7 \pm 0.3$ \\
\hline & 12 & $\mathrm{CH}_{2} \mathrm{Cl}_{2}$ & 493 & 512 & 753 & 1260 & 1230 & $0.07 \pm 0.01$ & 329 & $2.1 \pm 0.3$ & $28.3 \pm 0.3$ \\
\hline & 13 & $\mathrm{C}-\mathrm{C}_{6} \mathrm{H}_{12}{ }^{d}$ & 496 & 518 & 856 & 860 & 1570 & $0.12 \pm 0.02$ & 274 & $4.4 \pm 0.7$ & $32.1 \pm 0.7$ \\
\hline & 14 & 1-Octanol & 495 & 512 & 671 & 990 & 1390 & $0.24 \pm 0.03$ & 430 & $5.6 \pm 0.7$ & $17.7 \pm 0.7$ \\
\hline & 15 & $\mathrm{CHCl}_{3}$ & 495 & 512 & 671 & 1070 & 1340 & $0.10 \pm 0.01$ & 456 & $2.2 \pm 0.2$ & $19.7 \pm 0.2$ \\
\hline & 16 & $\mathrm{C}-\mathrm{C}_{6} \mathrm{H}_{10} \mathrm{O}^{d}$ & 495 & 511 & 633 & 1030 & 1390 & $0.07 \pm 0.01$ & 259 & $2.7 \pm 0.4$ & $35.9 \pm 0.4$ \\
\hline & 17 & Toluene & 497 & 517 & 778 & 980 & 1570 & $0.096 \pm 0.007$ & 434 & $2.2 \pm 0.2$ & $20.8 \pm 0.2$ \\
\hline & 18 & $\mathrm{PhCl}^{d}$ & 497 & 516 & 741 & 1070 & 1530 & $0.10 \pm 0.01$ & 473 & $2.1 \pm 0.2$ & $19.0 \pm 0.2$ \\
\hline
\end{tabular}

\footnotetext{
${ }^{a}$ Fluorescence quantum yield \pm one standard uncertainty. $\Phi$ determined vs. rhodamine $6 \mathrm{G}$ in water $\left(\Phi_{\mathrm{r}}=0.76\right)$ as a reference.

${ }^{b}$ The standard error on the fluorescence lifetime is $1 \mathrm{ps}$ [obtained from the diagonal elements of the covariance matrix available from the global analysis fit of decay traces recorded at three emission wavelengths $\left.\lambda_{\mathrm{em}}(515,520,525 \mathrm{~nm})\right] . \lambda_{\mathrm{ex}}=488 \mathrm{~nm}$.

${ }^{c}$ The propagated errors are calculated using the uncertainty (standard deviation) of $\Phi$ and the standard error of $\tau$.

${ }^{d}$ see Table 1.
}

Fluorescence features similar to those of 2-Ph and 3-Ph were found for the corresponding 2- and 3substituted phenylethynyl BODIPY dyes (2-Ethyn and 3-Ethyn). 3-Ethyn showed fluorescence properties comparable to those of 3-Ph, i.e., a narrow emission band ( $f w h m_{e m}=950 \pm 50 \mathrm{~cm}^{-1}$ ) with $\lambda_{\text {em }}(\max )$ in the range from $547 \mathrm{~nm}$ (in acetonitrile and acetone) to $557 \mathrm{~nm}$ (in toluene and chlorobenzene) and a small Stokes shift $(\Delta \bar{V}$ $=552 \pm 101 \mathrm{~cm}^{-1}$, averaged over all solvents). In analogy to what is found for 3-Ph, fwhm ${ }_{\text {abs }}$ of 3-Ethyn (1260 \pm $160 \mathrm{~cm}^{-1}$ ) is significantly larger than $\mathrm{fwhm}_{\mathrm{em}}$. Using eqn (1) and the average value of $\mathrm{fwhm}_{\mathrm{em}}$, an average Stokes shift $\Delta \bar{v}$ of $800 \mathrm{~cm}^{-1}$ is obtained for 3-Ethyn, which agrees marginally with the experimental average value of $\Delta \bar{v}$. However, based on the average value of fwhm abs an average value of $\Delta \bar{v}$ of $1430 \mathrm{~cm}^{-1}$ is calculated using eqn (1), which is ca. three times larger than the experimental value. Figure $1 \mathrm{~B}$ shows the fluorescence emission spectra of 3-Ethyn in a selection of solvents. 3-Ethyn exhibits large $\Phi$ values, from 0.77 (in cyclohexanone) to 1.00 in several solvents, which is in good agreement with previous reports. ${ }^{35,37}$ Likewise, the fluorescence lifetime $\tau$ decreases from $5.17 \mathrm{~ns}$ in methanol to $4.35 \mathrm{~ns}$ in chlorobenzene (Figure S8). These $\Phi$ and $\tau$ values involve an increase in $k_{\mathrm{f}}$ in more polarizable solvents, ranging from (1.6-1.7) $\times 10^{8} \mathrm{~s}^{-1}$ in acetonitrile and methanol to $(2.2-2.3) \times 10^{8} \mathrm{~s}^{-1}$ in chlorobenzene and toluene, combined with low values for $k_{\mathrm{nr}}$. As found for 3-Ph, the higher $k_{\mathrm{f}}$ values of 3-Ethyn are found for highly polarizable, nonpolar solvents (e.g., toluene and chlorobenzene) whereas polar, nonpolarizable solvents (e.g., methanol and acetonitrile) yield the lowest $k_{\mathrm{f}}$ values. Also in analogy with 3-Ph, the $k_{\mathrm{nr}}$ values of 3-Ethyn do not show a clear solvent dependence, but they always remain smaller than $k_{\mathrm{f}}$. 2-Ethyn displays a fluorescence behavior similar to that of 2-Ph: a broad emission band ( $f w h m_{e m}=1960 \pm 210 \mathrm{~cm}^{-1}$ ) with $\lambda_{\text {em }}$ (max) varying between $556 \mathrm{~nm}$ (in cyclohexane) and $569 \mathrm{~nm}$ (in butanenitrile) and a 3-fold larger Stokes shift 
$\Delta \bar{V}\left(1720 \pm 301 \mathrm{~cm}^{-1}\right.$, averaged over all solvents) than the corresponding 3-Ethyn $\left(\Delta \bar{V}=552 \pm 101 \mathrm{~cm}^{-1}\right)$ and 8Ethyn $\left(\Delta \bar{v}=464 \pm 33 \mathrm{~cm}^{-1}\right)$. In parallel with what was observed for 2-Ph, fwhmabs of 2-Ethyn $\left(2210 \pm 110 \mathrm{~cm}^{-1}\right)$ is

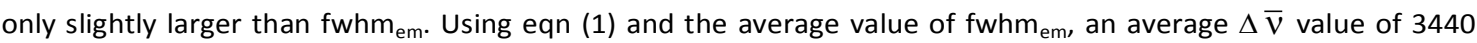
$\mathrm{cm}^{-1}$ is calculated for 2-Ethyn, which is again twice the experimental value. Based on the average value of

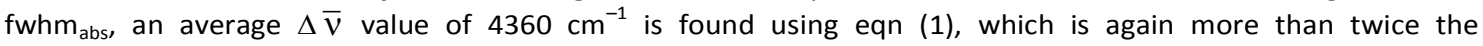
experimental value. The $\Phi$ values range from 0.20 (in cyclohexanone) to 0.72 (in toluene). The latter is slightly higher than the previously reported value of $0.61 .^{35}$ Our results for $\Phi$ of 2-Ethyn in THF, methanol and acetonitrile are in good agreement with previously reported data. ${ }^{35}$ In similarity with 2-Ph, the fluorescence decay rate constant $k_{\mathrm{f}}$ of 2-Ethyn, with a similar average value of $(1.1 \pm 0.3) \times 10^{8} \mathrm{~s}^{-1}$, does not display any clear solvent dependent trend. The solvent effect on $\boldsymbol{k}_{\mathrm{nr}}$ of 2-Ethyn is similar to that of 2-Ph. As discussed for 2-Ph, the larger value of $k_{\mathrm{nr}}$ of 2-Ethyn compared to 3-Ethyn can be related to the broader absorption and emission bands and the larger Stokes shift. As observed for 2-Ph and 3-Ph, the values of $k_{\mathrm{f}}$ of 2-Ethyn $\left[(1.1 \pm 0.3) \times 10^{8} \mathrm{~s}^{-1}\right]$ amount to about $50 \%$ of those of 3-Ethyn [(1.9 \pm 0.2$\left.) \times 10^{8} \mathrm{~s}^{-1}\right]$. With these $k_{\mathrm{f}}$ and $k_{\mathrm{nr}}$ values, the fluorescence lifetime $\tau$ of 2 Ethyn is in the range from 3.70 to 5.09 ns (Figure S8). Table 3 compiles the spectroscopic and photophysical properties of 2-Ethyn and 3-Ethyn. These data confirm the different performance of BODIPY dyes substituted at the 2- and 3-positions. For 8-Ethyn, the average Stokes shift calculated using eqn (1) with the average value of fwhm $\mathrm{em}_{1}, 1390 \mathrm{~cm}^{-1}$, amounts to $1720 \mathrm{~cm}^{-1}$, which is nearly four times the experimental value of $464 \mathrm{~cm}^{-1}$. However, when the average fwhm abs value, $960 \mathrm{~cm}^{-1}$, is used an average value of $820 \mathrm{~cm}^{-1}$ is calculated for $\Delta \bar{v}$, which is still nearly twice the experimental value. When the phenyl-substituted BODIPYs are compared to their ethynylphenyl-substituted counterparts, the average values of $\Delta \bar{v}$, fwhm $\mathrm{fwbs}_{\mathrm{a}}$ and $\mathrm{fwhm}_{\mathrm{em}}$ are largest for the 2substituted BODIPYs. For 3-substituted BODIPYs, fwhm $\mathrm{fbs}_{\text {abs }}$ is larger than $\mathrm{fwhm}_{\mathrm{em}}$, which indicates a steeper PES in the excited state compared to the ground state for the rotation of the substituent, while the opposite (i.e., steeper PES in the ground state than in the excited state) occurs for the 8-substituted BODIPYs for which fwhm abs $_{\text {s }}$ is smaller than fwhm $\mathrm{fm}_{\mathrm{em}}$. For the 2-subsituted BODIPYs, fwhm $\mathrm{wbs}_{\text {and }}$ fwhm $\mathrm{fm}_{\mathrm{er}}$ are nearly the same, but are much larger than those observed for the 3- and 8-substituted BODIPYs indicating a larger difference in the equilibrium position of the rotation angle of the substituent. The Stokes shifts $\Delta \bar{v}$ are the smallest for the 8-substituted analogues and the largest for the 2-substituted ones.

In contrast to 8-Ph, phenylethynyl substitution at the meso-position (8-Ethyn) did not result in such a large enhancement of nonradiative deactivation, and 8-Ethyn exhibited large $\Phi(0.550-0.715)$ and $\tau(6.72-7.60 \mathrm{~ns})$ values (Table S2). ${ }^{27}$ In parallel with 3-Ph and 3-Ethyn, highly polarizable, nonpolar solvents (e.g., toluene and chlorobenzene) yield higher $k_{\mathrm{f}}$ values of 8-Ethyn than polar, nonpolarizable solvents do (e.g., methanol and acetonitrile), with polarizability being the major factor determining the magnitude of $k_{\mathrm{f}}$. The larger values of $\Phi$ and smaller values of $k_{\mathrm{nr}}$ observed for 8-Ethyn in contrast to 8-Ph are caused by the extended conjugation of the $\pi$-electrons within the triple bond of the meso-substituent. Due to the absence of steric hindrance (in contrast to 8-Ph) there is no exciton phonon coupling with the rotation of the substituent, which could induce a radiationless decay. The most red-shifted $\lambda_{\text {abs }}(\max )$ of 8-Ethyn in the series of phenylethynyl compounds are in contrast to the most blue-shifted $\lambda_{\text {abs }}$ (max) of 8-Ph in the series of phenyl-substituted dyes. 
Table 3. Spectroscopic and photophysical data of 3-Ethyn and 2-Ethyn, as a function of solvent. The solvents are numbered according to increasing refractive index $n$.

\begin{tabular}{|c|c|c|c|c|c|c|c|c|c|c|c|}
\hline \multirow[t]{2}{*}{ Product } & & \multirow[t]{2}{*}{ Solvent } & \multirow{2}{*}{$\begin{array}{c}\lambda_{\text {abs }} \\
(\max ) \\
{[\mathrm{nm}]}\end{array}$} & \multirow{2}{*}{$\begin{array}{c}\lambda_{\text {em }} \\
(\max ) \\
{[\mathrm{nm}]}\end{array}$} & \multirow{2}{*}{$\begin{array}{c}\Delta \bar{v} \\
{\left[\mathrm{~cm}^{-1}\right]}\end{array}$} & \multirow{2}{*}{$\begin{array}{c}\text { fwhm }{ }_{a b s} \\
{\left[\mathrm{~cm}^{-1}\right]}\end{array}$} & \multirow{2}{*}{$\begin{array}{c}\text { fwhm }{ }_{\mathrm{em}} \\
{\left[\mathrm{cm}^{-1}\right]}\end{array}$} & \multirow[t]{2}{*}{$\Phi^{a}$} & \multirow{2}{*}{$\begin{array}{c}\tau^{b} \\
{[\mathrm{~ns}]}\end{array}$} & \multirow{2}{*}{$\begin{array}{c}k_{f}^{c} \\
{\left[10^{8} s^{-1}\right]}\end{array}$} & \multirow{2}{*}{$\begin{array}{c}k_{\mathrm{nr}}{ }^{c} \\
{\left[10^{8} \mathrm{~s}^{-1}\right]}\end{array}$} \\
\hline & & & & & & & & & & & \\
\hline 3- & 1 & $\mathrm{CH}_{3} \mathrm{OH}$ & 530 & 548 & 620 & 1330 & 990 & $0.86 \pm 0.01$ & 5.17 & $1.66 \pm 0.02$ & $0.27 \pm 0.02$ \\
\hline \multirow[t]{17}{*}{ Ethyn } & 2 & $\mathrm{CH}_{3} \mathrm{CN}$ & 525 & 547 & 766 & 1640 & 1000 & $0.83 \pm 0.01$ & 5.14 & $1.61 \pm 0.02$ & $0.33 \pm 0.02$ \\
\hline & 3 & $\left(\mathrm{C}_{2} \mathrm{H}_{5}\right)_{2} \mathrm{O}$ & 536 & 551 & 508 & 1090 & 910 & $0.87 \pm 0.03$ & 5.15 & $1.69 \pm 0.06$ & $0.25 \pm 0.06$ \\
\hline & 4 & Acetone & 529 & 547 & 622 & 1430 & 1000 & $0.88 \pm 0.01$ & 5.12 & $1.72 \pm 0.02$ & $0.23 \pm 0.02$ \\
\hline & 5 & EtOAc $^{d}$ & 532 & 548 & 549 & 1280 & 940 & $0.84 \pm 0.01$ & 4.92 & $1.71 \pm 0.02$ & $0.33 \pm 0.02$ \\
\hline & 6 & 2-Propanol & 535 & 552 & 576 & 1230 & 920 & $0.845 \pm 0.001$ & 4.95 & $1.71 \pm 0.01$ & $0.31 \pm 0.01$ \\
\hline & 7 & $\mathrm{PrCN}^{d}$ & 530 & 549 & 653 & 1460 & 1000 & $0.91 \pm 0.03$ & 4.96 & $1.83 \pm 0.06$ & $0.18 \pm 0.06$ \\
\hline & 8 & $\mathrm{Bu}_{2} \mathrm{O}^{d}$ & 540 & 553 & 435 & 1030 & 860 & $0.868 \pm 0.003$ & 4.87 & $1.78 \pm 0.01$ & $0.27 \pm 0.01$ \\
\hline & 9 & $\mathrm{THF}^{d}$ & 534 & 551 & 578 & 1250 & 960 & $0.84 \pm 0.01$ & 4.76 & $1.76 \pm 0.02$ & $0.34 \pm 0.02$ \\
\hline & 10 & 1-Pentanol & 538 & 554 & 537 & 1220 & 920 & $0.86 \pm 0.02$ & 4.82 & $1.78 \pm 0.04$ & $0.29 \pm 0.04$ \\
\hline & 11 & 1,4-Dioxane & 535 & 552 & 576 & 1380 & 990 & $1.00 \pm 0.02$ & 4.65 & $2.15 \pm 0.04$ & $0.00 \pm 0.04$ \\
\hline & 12 & $\mathrm{CH}_{2} \mathrm{Cl}_{2}$ & 535 & 554 & 641 & 1380 & 940 & $0.90 \pm 0.01$ & 4.78 & $1.88 \pm 0.02$ & $0.21 \pm 0.02$ \\
\hline & 13 & $\mathrm{C}-\mathrm{C}_{6} \mathrm{H}_{12}{ }^{d}$ & 545 & 554 & 298 & 1100 & 870 & $1.0 \pm 0.1$ & 4.70 & $2.1 \pm 0.2$ & $0.0 \pm 0.2$ \\
\hline & 14 & 1-Octanol & 540 & 555 & 501 & 1160 & 950 & $0.90 \pm 0.04$ & 4.71 & $1.91 \pm 0.09$ & $0.21 \pm 0.09$ \\
\hline & 15 & $\mathrm{CHCl}_{3}$ & 539 & 554 & 502 & 1110 & 880 & $0.86 \pm 0.02$ & 4.77 & $1.80 \pm 0.04$ & $0.29 \pm 0.04$ \\
\hline & 16 & $\mathrm{C}-\mathrm{C}_{6} \mathrm{H}_{10} \mathrm{O}^{d}$ & 534 & 552 & 611 & 1330 & 1010 & $0.77 \pm 0.08$ & 4.60 & $1.7 \pm 0.2$ & $0.5 \pm 0.2$ \\
\hline & 17 & Toluene & 543 & 557 & 463 & 1110 & 940 & $1.00 \pm 0.05$ & 4.43 & $2.3 \pm 0.1$ & $0.0 \pm 0.1$ \\
\hline & 18 & $\mathrm{PhCl}^{d}$ & 542 & 557 & 497 & 1220 & 960 & $0.95 \pm 0.09$ & 4.35 & $2.2 \pm 0.2$ & $0.1 \pm 0.2$ \\
\hline 2- & 1 & $\mathrm{CH}_{3} \mathrm{OH}$ & 509 & 566 & 1979 & 2270 & 2210 & $0.38 \pm 0.02$ & 3.70 & $1.03 \pm 0.05$ & $1.68 \pm 0.05$ \\
\hline \multirow[t]{17}{*}{ Ethyn } & 2 & $\mathrm{CH}_{3} \mathrm{CN}$ & 503 & 567 & 2244 & 2520 & 2320 & $0.337 \pm 0.004$ & 4.05 & $0.83 \pm 0.01$ & $1.64 \pm 0.01$ \\
\hline & 3 & $\left(\mathrm{C}_{2} \mathrm{H}_{5}\right)_{2} \mathrm{O}$ & 516 & 560 & 1523 & 2160 & 1880 & $0.59 \pm 0.03$ & 5.09 & $1.16 \pm 0.06$ & $0.81 \pm 0.06$ \\
\hline & 4 & Acetone & 506 & 565 & 2064 & 2200 & 2190 & $0.47 \pm 0.02$ & 4.32 & $1.09 \pm 0.05$ & $1.23 \pm 0.05$ \\
\hline & 5 & EtOAc $^{d}$ & 509 & 562 & 1853 & 2220 & 2020 & $0.547 \pm 0.004$ & 4.63 & $1.18 \pm 0.01$ & $0.98 \pm 0.01$ \\
\hline & 6 & 2-Propanol & 513 & 566 & 1825 & 2260 & 2030 & $0.55 \pm 0.03$ & 4.36 & $1.26 \pm 0.07$ & $1.03 \pm 0.07$ \\
\hline & 7 & $\mathrm{PrCN}^{d}$ & 507 & 569 & 2149 & 2270 & 2190 & $0.24 \pm 0.01$ & 4.27 & $0.56 \pm 0.02$ & $1.78 \pm 0.02$ \\
\hline & 8 & $\mathrm{Bu}_{2} \mathrm{O}^{d}$ & 521 & 559 & 1305 & 2080 & 1710 & $0.61 \pm 0.05$ & 4.93 & $1.2 \pm 0.1$ & $0.8 \pm 0.1$ \\
\hline & 9 & $\mathrm{THF}^{d}$ & 513 & 562 & 1700 & 2190 & 1980 & $0.588 \pm 0.001$ & 4.58 & $1.28 \pm 0.01$ & $0.90 \pm 0.01$ \\
\hline & 10 & 1-Pentanol & 516 & 565 & 1681 & 2240 & 1970 & $0.55 \pm 0.03$ & 4.47 & $1.23 \pm 0.07$ & $1.01 \pm 0.07$ \\
\hline & 11 & 1,4-Dioxane & 513 & 559 & 1604 & 2140 & 1880 & $0.65 \pm 0.02$ & 4.83 & $1.35 \pm 0.04$ & $0.72 \pm 0.04$ \\
\hline & 12 & $\mathrm{CH}_{2} \mathrm{Cl}_{2}$ & 513 & 566 & 1825 & 2220 & 2070 & $0.55 \pm 0.02$ & 4.54 & $1.21 \pm 0.04$ & $0.99 \pm 0.05$ \\
\hline & 13 & c- $\mathrm{C}_{6} \mathrm{H}_{12}{ }^{d}$ & 525 & 556 & 1062 & 2110 & 1450 & $0.71 \pm 0.04$ & 4.92 & $1.44 \pm 0.08$ & $0.59 \pm 0.08$ \\
\hline & 14 & 1-Octanol & 517 & 565 & 1643 & 2270 & 1920 & $0.56 \pm 0.04$ & 4.69 & $1.19 \pm 0.09$ & $0.94 \pm 0.09$ \\
\hline & 15 & $\mathrm{CHCl}_{3}$ & 517 & 565 & 1643 & 2270 & 1730 & $0.45 \pm 0.04$ & 4.74 & $0.95 \pm 0.08$ & $1.16 \pm 0.09$ \\
\hline & 16 & $\mathrm{C}-\mathrm{C}_{6} \mathrm{H}_{10} \mathrm{O}^{d}$ & 511 & 567 & 1933 & 2160 & 2100 & $0.20 \pm 0.03$ & 4.34 & $0.46 \pm 0.07$ & $1.84 \pm 0.07$ \\
\hline & 17 & Toluene & 521 & 562 & 1400 & 2040 & 1750 & $0.72 \pm 0.02$ & 4.68 & $1.54 \pm 0.04$ & $0.60 \pm 0.04$ \\
\hline & 18 & $\mathrm{PhCl}^{d}$ & 520 & 565 & 1532 & 2090 & 1880 & $0.61 \pm 0.06$ & 4.55 & $1.3 \pm 0.1$ & $0.9 \pm 0.1$ \\
\hline
\end{tabular}

\footnotetext{
${ }^{a}$ Fluorescence quantum yield \pm one standard uncertainty. $\Phi$ determined vs. rhodamine $6 \mathrm{G}$ in water $\left(\Phi_{\mathrm{r}}=0.76\right)$ as a reference.
}

${ }^{b}$ Fluorescence lifetime. The standard errors are obtained from the diagonal elements of the covariance matrix available from the global analysis fit of decay traces recorded at three emission wavelengths $\lambda_{\text {em }}$ and are between 11 and 14 ps for 3-Ethyn and between 11 and 14 ps for 2-Ethyn. For both 3-Ethyn and 2-Ethyn: $\lambda_{\mathrm{ex}}=488 \mathrm{~nm}$, and $\lambda_{\mathrm{em}}=560,563,566 \mathrm{~nm}$.

${ }^{c}$ The propagated errors are calculated using the uncertainty (standard deviation) of $\Phi$ and the standard error of $\tau$.

${ }^{d}$ See Table 1.

Finally, 3-Styryl - substituted at the 3-position with the (E)-styryl group - also shows fluorescence emission spectral features in line with the other 3-substituted dyes. 3-Styryl reveals a narrow $\mathrm{S}_{0} \leftarrow \mathrm{S}_{1}$ emission band ( $f w h m_{e m}=740 \pm 30 \mathrm{~cm}^{-1}$ ), mirror image of the absorption band with $\lambda_{\text {em }}$ (max) undergoing a bathochromic shift from $559 \mathrm{~nm}$ in acetonitrile to $570 \mathrm{~nm}$ in chlorobenzene. The styryl substituent at the 3-position causes an additional red shift in the absorption spectra compared to 3-Ph and 3-Ethyn. However, this effect is less present in the emission spectra, leading to very small Stokes shift values $\left(\Delta \bar{v}=297 \pm 30 \mathrm{~cm}^{-1}\right.$, averaged over all the solvents). The average $\Delta \bar{v}$ values calculated from the average value of fwhmem $\left(740 \mathrm{~cm}^{-1}\right)$ using eqn (1) amounts to $480 \mathrm{~cm}^{-1}$ which is close to the average experimental value $297 \mathrm{~cm}^{-1}$. Using the average value of fwhmabs $(800$ 
$\mathrm{cm}^{-1}$ ) the value of $570 \mathrm{~cm}^{-1}$ is obtained for $\Delta \bar{v}$. When compared to the other 3-substituted derivatives, the phenyl substitution in 3-Ph is causing the largest Stokes shifts $\left(\Delta \bar{V}=990 \pm 67 \mathrm{~cm}^{-1}\right)$, followed by 3-Ethyn $(\Delta \bar{V}=$ $\left.552 \pm 101 \mathrm{~cm}^{-1}\right)$ and finally 3-Styryl $\left(\Delta \bar{V}=297 \pm 30 \mathrm{~cm}^{-1}\right)$. The different conjugation of the substituents investigated at the 3-position can be rationalized since phenyl substitution creates the largest relaxation of the excited state, whereas styryl substitution produces further stabilization of the ground state. Figure $2 \mathrm{~B}$ shows selected examples of 3-Styryl emission spectra. The $\Phi$ and $\tau$ values for 3-Styryl decline in more polarizable solvents: $\Phi$ decreases from 0.66 in acetonitrile to 0.42 in cyclohexanone, whereas $\tau$ changes from $4.66 \mathrm{~ns}$ in diethyl ether to $3.89 \mathrm{~ns}$ in chlorobenzene. These results can be rationalized as the value of $k_{\mathrm{f}}$ remains largely invariable in the different solvents [average $k_{\mathrm{f}}=(1.3 \pm 0.1) \times 10^{8} \mathrm{~s}^{-1}$ ], whereas $k_{\mathrm{nr}}$ of 3-Styryl increases in more polarizable solvents (from $0.75 \times 10^{8} \mathrm{~s}^{-1}$ in acetonitrile to $1.26 \times 10^{8} \mathrm{~s}^{-1}$ in chlorobenzene). The $\Phi$ values reported herein are slightly lower than previously published values in methanol, acetonitrile, THF and toluene; ${ }^{35}$ however, our results are self consistent between many other different solvents. The spectroscopic properties of 3-Styryl are presented in Table 4. As mentioned above, 2-Styryl and 8-Styryl are unstable compounds, exhibiting timedependent, dual-band emission features (see ESI and Figures S5 and S6 for more details).

Table 4. Spectroscopic and photophysical data of 3-Styryl as a function of solvent. The solvents are numbered according to increasing refractive index $n$.

\begin{tabular}{|c|c|c|c|c|c|c|c|c|c|c|c|}
\hline Product & & Solvent & $\begin{array}{c}\lambda_{\text {abs }}(\max ) \\
{[\mathrm{nm}]}\end{array}$ & $\begin{array}{c}\lambda_{\text {em }}(\max ) \\
{[\mathrm{nm}]}\end{array}$ & $\begin{array}{c}\Delta \bar{V} \\
{\left[\mathrm{~cm}^{-1}\right]}\end{array}$ & $\begin{array}{c}\text { fwhm } \\
{\left[\mathrm{cm}^{-1}\right]}\end{array}$ & $\begin{array}{c}\text { fwhm }{ }_{\mathrm{em}} \\
{\left[\mathrm{cm}^{-1}\right]}\end{array}$ & $\Phi^{a}$ & $\begin{array}{c}\tau^{b} \\
{[\mathrm{~ns}]}\end{array}$ & $\begin{array}{c}k_{\mathrm{f}}^{c} \\
{\left[10^{8} \mathrm{~s}^{-1}\right]}\end{array}$ & $\begin{array}{c}k_{\mathrm{nr}}{ }^{c} \\
{\left[10^{8} \mathrm{~s}^{-1}\right]}\end{array}$ \\
\hline \multirow[t]{17}{*}{ 3-Styryl } & 1 & $\mathrm{CH}_{3} \mathrm{OH}$ & 550 & 560 & 325 & 860 & 760 & $0.60 \pm 0.02$ & 4.62 & $1.30 \pm 0.04$ & $0.87 \pm 0.04$ \\
\hline & 2 & $\mathrm{CH}_{3} \mathrm{CN}$ & 549 & 559 & 326 & 890 & 780 & $0.66 \pm 0.02$ & 4.54 & $1.45 \pm 0.04$ & $0.75 \pm 0.05$ \\
\hline & 3 & $\left(\mathrm{C}_{2} \mathrm{H}_{5}\right)_{2} \mathrm{O}$ & 553 & 561 & 258 & 760 & 730 & $0.58 \pm 0.01$ & 4.66 & $1.24 \pm 0.02$ & $0.90 \pm 0.02$ \\
\hline & 4 & Acetone & 550 & 560 & 325 & 860 & 770 & $0.60 \pm 0.02$ & 4.40 & $1.36 \pm 0.05$ & $0.91 \pm 0.05$ \\
\hline & 5 & $\mathrm{EtOAc}^{d}$ & 551 & 561 & 324 & 830 & 750 & $0.61 \pm 0.02$ & 4.53 & $1.35 \pm 0.04$ & $0.86 \pm 0.05$ \\
\hline & 6 & 2-Propanol & 554 & 563 & 289 & 820 & 750 & $0.57 \pm 0.01$ & 4.42 & $1.29 \pm 0.02$ & $0.97 \pm 0.02$ \\
\hline & 7 & $\mathrm{Bu}_{2} \mathrm{O}^{d}$ & 556 & 564 & 255 & 750 & 710 & $0.48 \pm 0.03$ & 4.56 & $1.05 \pm 0.07$ & $1.14 \pm 0.07$ \\
\hline & 8 & 1-Butanol & 555 & 565 & 319 & 820 & 740 & $0.59 \pm 0.04$ & 4.38 & $1.35 \pm 0.09$ & $0.94 \pm 0.09$ \\
\hline & 9 & $\mathrm{THF}^{d}$ & 556 & 566 & 318 & 840 & 770 & $0.55 \pm 0.01$ & 4.22 & $1.30 \pm 0.02$ & $1.07 \pm 0.03$ \\
\hline & 10 & 1-Pentanol & 556 & 566 & 318 & 810 & 750 & $0.48 \pm 0.01$ & 4.30 & $1.12 \pm 0.02$ & $1.21 \pm 0.03$ \\
\hline & 11 & 1,4-Dioxane & 555 & 564 & 288 & 800 & 740 & $0.56 \pm 0.02$ & 4.26 & $1.31 \pm 0.05$ & $1.03 \pm 0.05$ \\
\hline & 12 & $\mathrm{CH}_{2} \mathrm{Cl}_{2}$ & 556 & 565 & 286 & 820 & 720 & $0.59 \pm 0.02$ & 4.29 & $1.38 \pm 0.05$ & $0.96 \pm 0.05$ \\
\hline & 13 & $\mathrm{C}-\mathrm{C}_{6} \mathrm{H}_{12}{ }^{d}$ & 558 & 565 & 222 & 660 & 650 & $0.53 \pm 0.01$ & 4.32 & $1.23 \pm 0.02$ & $1.09 \pm 0.03$ \\
\hline & 14 & $\mathrm{CHCl}_{3}$ & 559 & 569 & 314 & 780 & 730 & $0.53 \pm 0.08$ & 4.24 & $1.3 \pm 0.2$ & $1.1 \pm 0.2$ \\
\hline & 15 & $\mathrm{c}-\mathrm{C}_{6} \mathrm{H}_{10} \mathrm{O}^{d}$ & 555 & 565 & 319 & 790 & 750 & $0.42 \pm 0.02$ & 4.08 & $1.03 \pm 0.05$ & $1.42 \pm 0.05$ \\
\hline & 16 & Toluene & 560 & 569 & 282 & 760 & 710 & $0.52 \pm 0.02$ & 3.93 & $1.32 \pm 0.05$ & $1.22 \pm 0.05$ \\
\hline & 17 & $\mathrm{PhCl}^{d}$ & 561 & 570 & 281 & 770 & 720 & $0.51 \pm 0.01$ & 3.89 & $1.31 \pm 0.03$ & $1.26 \pm 0.03$ \\
\hline
\end{tabular}

${ }^{a}$ Fluorescence quantum yield \pm one standard uncertainty. $\Phi$ determined vs. rhodamine $6 \mathrm{G}$ in water $\left(\Phi_{\mathrm{r}}=0.76\right)$ as a reference.

${ }^{b}$ Fluorescence lifetime. The standard errors are obtained from the diagonal elements of the covariance matrix available from the global analysis fit of decay traces recorded at three emission wavelengths $\lambda_{\mathrm{em}}(560,565$ and $570 \mathrm{~nm})$ and are between 12 and $16 \mathrm{ps} . \lambda_{\mathrm{ex}}=532 \mathrm{~nm}$.

${ }^{c}$ The propagated errors are calculated using the uncertainty (standard deviation) of $\Phi$ and the standard error of $\tau$.

${ }^{d}$ See Table 1.

\section{Solvatochroism.}

It is useful to determine the origin of the solvent-dependent spectral changes by applying the most recent, comprehensive treatment of the solvent effect (based on a set of four empirical, complementary, mutually independent solvent scales, i.e., dipolarity, polarizability, acidity and basicity of the medium) described by Catalán. ${ }^{36}$ In this method, the polarizability and dipolarity of a particular solvent are characterized by the parameters SP and SdP, respectively, whereas solvent acidity and basicity are described by the scales SA and SB, respectively. The $\{S A, S B, S P, S d P\}$ values for a large number of solvents can be found in the literature. ${ }^{36}$ Mathematically, the solvent effect on the physicochemical observable $y$ can be expressed by the multilinear eqn (2):

$y=y_{0}+a_{\mathrm{SA}} \mathrm{SA}+b_{\mathrm{SB}} \mathrm{SB}+c_{\mathrm{SP}} \mathrm{SP}+d_{\mathrm{SdP}} \mathrm{SdP}$ 
where $y_{0}$ denotes the physicochemical property of interest in the gas phase; $a_{\mathrm{SA}}, b_{\mathrm{SB}}, c_{\mathrm{SP}}$ and $d_{\mathrm{SdP}}$ are regression coefficients that describe the sensitivity of the property $y$ to the various solvent-solute interaction mechanisms; and $\{\mathrm{SA}, \mathrm{SB}, \mathrm{SP}, \mathrm{SdP}\}$ are independent solvent parameters (indices) accounting for the various types of solventsolute interactions.

The spectroscopic observables $y$ analyzed in this paper are the absorption maxima $\bar{v}_{\text {abs }}\left[=1 / \lambda_{\text {abs }}(\max )\right]$ and the fluorescence emission maxima $\bar{v}_{\mathrm{em}}\left[=1 / \lambda_{\mathrm{em}}(\max )\right]$, both expressed in $\mathrm{cm}^{-1}$. The results of the fits of $y=\bar{v}_{\mathrm{abs}}$ and $y=\bar{v}_{\text {em }}$ according to eqn (2) are compiled in Table S3 for 3-Ethyn, 2-Ethyn and 8-Ethyn, Table S4 for 3-Ph, 2$\mathrm{Ph}$ and 8-Ph, and Table S5 for 3-Styryl. Making use of the Catalán solvent scales $\{\mathrm{SA}, \mathrm{SB}, \mathrm{SP}, \mathrm{SdP}\}$ [eqn (2)] gives excellent fits of $y=\overline{\mathbf{V}}_{\text {abs }}$ of 3-Ph, 2-Ph, 8-Ph, 3-Ethyn, 2-Ethyn, 8-Ethyn and 3-Styryl for the solvents listed in the respective Tables (1-4 and S2), using the correlation coefficient $r$ as goodness-of-fit criterion $[r \geq 0.928$, Tables S3-

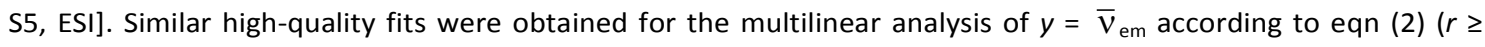
0.844 , Tables S3-S5, ESI).

The unique, extra benefit of the generalized (i.e. Catalán) treatment of the solvent effect is that it allows one to separate the relative contributions of dipolarity, polarizability, acidity and basicity of the medium. Therefore, we utilized the new methodology to resolve which solvent properties are primarily responsible for the observed shifts of $\bar{v}_{\text {abs }}$ and $\bar{v}_{\text {em }}$. The relative importance of each of the $\{$ SA, SB, SP, SdP\} solvent scales was studied by omitting in turn one or two solvent scales from the regression analysis [eqn (2)]. These analyses (Tables S3-S5, ESI) clearly identify solvent dipolarity and polarizability as critical parameters accounting for the experimental solvatochromic shifts of $\bar{v}_{\text {abs }}$ and $\bar{v}_{\text {em }}$ of 3-Ethyn, 2-Ethyn, 8-Ethyn, 3-Ph, 2-Ph, 8-Ph and 3-Styryl (see ESI for details).

Some general trends in the results of the Catalán analyses can be observed. For the absorption spectra $\left(\overline{\mathrm{V}}_{\mathrm{abs}}\right)$ of all the compounds, $d_{\mathrm{SdP}}$ is positive and ranges from 200 to 700, while $c_{\mathrm{SP}}$ has much larger, negative values ranging between ca. -1100 and -1450 . This indicates that the major effect of the solvent on the absorption spectra is related to the polarizability: an increasing solvent polarizability induces a red shift of $\lambda_{\text {abs }}$ (max). For the emission spectra $\left(\bar{v}_{\mathrm{em}}\right)$ of the 3- and 8-substituted BODIPYs, the solvent dependence resembles that of the absorption spectra: $c_{S P}$ is negative with values between -670 and -1570 , while $d_{S d P}$ is positive, but with smaller values ranging from 130 to 710 . For these dyes, the effect of solvent polarity on $\lambda_{\text {em }}(\max )$ is the same as for $\lambda_{\text {abs }}(\max )$ : a higher polarizability induces a red shift of $\lambda_{\mathrm{em}}(\max )$. The situation for the emission spectra of the 2 substituted BODPYs 2-Ph and 2-Ethyn is different: negative values are recovered for both $c_{\mathrm{SP}}$ and $d_{\mathrm{SdP}}$. How $\lambda_{\mathrm{em}}(\max )$ of these dyes moves as a function of the solvent used depends on the relative weights of solvent polarizability $\left(c_{\mathrm{SP}}\right)$ and dipolar polarity $\left(d_{\mathrm{SdP}}\right)$. The seemingly erratic dependence of $\lambda_{\mathrm{em}}(\mathrm{max})$ of 2-Ph and 2-Ethyn as a function of solvent refractive index $n$ (Table S1) can be rationalized by the substantial influence of solvent dipolarity $(\varepsilon)$. The correlation of $\lambda_{\mathrm{em}}(\max )$ of 2-Ph or 2-Ethyn with solvent polarizability is less obvious as compared to that of the corresponding $\lambda_{\text {abs }}(\max )$. The negative $c_{\mathrm{SP}}$ and $d_{\mathrm{SdP}}$ produce, besides a red shift of $\lambda_{\mathrm{em}}(\max )$ with increasing $n$ (polarizability), also a red shift with increasing $\varepsilon$ (dipolarity).

Since the first report on the use of the solvent scales $\{\mathrm{SA}, \mathrm{SB}, \mathrm{SP}, \mathrm{SdP}\}{ }^{36}$ the physicochemical observables $y$ in eqn (2) have been almost exclusively the spectroscopic parameters $\bar{v}_{\text {abs }}$ and $\bar{v}_{\text {em }}$. A plausible reason may be that the accurate determination of the absorption $\left[\lambda_{\mathrm{abs}}(\max )=1 / \bar{v}_{\mathrm{abs}}\right]$ and emission $\left[\lambda_{\mathrm{em}}(\max )=1 / \bar{v}_{\mathrm{em}}\right]$ maxima is straightforward when a wavelength-calibrated spectrophotometer and a wavelength-calibrated, fully corrected both for the excitation and emission channel - spectrofluorometer are utilized. In principle, however, any solventinfluenced, physicochemical observable can be analyzed using the Catalán approach to determine which solvent property is primarily responsible for its experimental, solvent-dependent behavior. As an example, Figure S10 in the ESI shows that solvent dipolarity, $\mathrm{SdP}$, is an important factor in the variation of fwhm $\mathrm{m}_{\mathrm{abs}}$ and fwhm $\mathrm{fm}_{\mathrm{em}}$. In a pioneering paper, we analyzed the solvent-dependent behavior of the kinetic parameters $k_{\mathrm{f}}$ and $k_{\mathrm{nr}}$ of three boron dipyrromethene dyes. ${ }^{44}$ Since $k_{\mathrm{f}}(=\Phi / \tau)$ and $k_{\mathrm{nr}}[(1-\Phi) / \tau]$ are calculated from the values of fluorescence quantum yield $(\Phi)$ and lifetime $(\tau)$, obtaining accurate values of $k_{\mathrm{f}}$ and $k_{\mathrm{nr}}$ depends critically on the accuracy with which $\Phi$ and $\tau$ are measured. These measurements are generally more challenging than those of $\bar{v}_{\text {abs }}$ and $\bar{v}_{\text {em }}$. One can expect a higher degree of uncertainty of the $k_{\mathrm{f}}$ and $k_{\mathrm{nr}}$ values, even when the measurements of $\Phi$ and $\tau$ have been carefully executed by skilled researchers.

The analyses of the $k_{\mathrm{f}}$ values of 2-Ph, 2-Ethyn, 8-Ph and 3-Styryl using $\{\mathrm{SA}, \mathrm{SB}, \mathrm{SP}, \mathrm{SdP}\}$ [eqn (2)], and as a function of $\varepsilon$ [eqn (3)] and $f\left(n^{2}\right)$ [eqn (4)] indicate that there is no clear trend in the dependence of $k_{\mathrm{f}}$ on solvent (di)polarity (or $\varepsilon$ ) or polarizability (or $n$ ) for these compounds. Conversely, analyses of $y=k_{\mathrm{f}}$ of 3-Ph, 3-Ethyn and 8-Ethyn according to eqn (2) recover positive $c_{S P}$ and significantly (4-5-fold) smaller, negative $d_{S d P}$ estimated values (Table S6). Hence, higher polarizability leads to higher $k_{\mathrm{f}}$ values whereas higher polarity yields lower $k_{\mathrm{f}}$ values. This is in agreement with the observation that the higher $k_{f}$ values of these dyes are found for highly polarizable, nonpolar solvents (e.g., toluene and chlorobenzene) whereas polar, nonpolarizable solvents (e.g., methanol and acetonitrile) yield the lowest $k_{\mathrm{f}}$ values. Extra linear fits of $y=k_{\mathrm{f}}$ as a function of $\varepsilon[(\mathrm{di})$ polarity, eqn 
(3)] and as a function of $f\left(n^{2}\right)$ [polarizability, eqn(4)] corroborate that polarizability $(n)$ is more effective than polarity $(\varepsilon)$ in influencing the value of $k_{\mathrm{f}}$ (Table S6).

$y=y_{0}+a \varepsilon$

$y=y_{0}+b f\left(n^{2}\right)$ with $f\left(n^{2}\right)=\left(n^{2}-1\right) /\left(2 n^{2}+1\right)$

Analyses of $k_{\mathrm{nr}}$ of 3-Ph and 3-Ethyn as a function of $\{\mathrm{SA}, \mathrm{SB}, \mathrm{SP}, \mathrm{SdP}\}$ [eqn (2)], $\varepsilon$ [eqn (3)] and $f\left(n^{2}\right)$ [eqn (4)] do not show any clear solvent dependence. The solvent effect on $k_{\mathrm{f}}, k_{\mathrm{nr}}, \lambda_{\mathrm{abs}}(\max )$ and $\lambda_{\mathrm{em}}(\max )$ of 3-Ph is in complete agreement with that of 3-Ethyn. Fitting the $k_{\mathrm{nr}}$ values of 8-Ethyn according to eqn (2) gives a good fit with positive, nearly equal $c_{\mathrm{SP}}$ and $d_{\mathrm{SdP}}$ estimates (Table S6), indicating that polarity and polarizability have equal importance in influencing the value of $k_{\mathrm{nr}}$. The multilinear fit of $y=k_{\mathrm{nr}}$ of 2-Ph according to eqn (2) recovers a small, negative $c_{\mathrm{SP}}$ and a 3 -fold larger positive $d_{\mathrm{SdP}}$ value (Table S6), accounting for the large $k_{\mathrm{nr}}\left(>10^{8} \mathrm{~s}^{-1}\right.$ ) values in the more polar solvents (methanol, acetonitrile, acetone, 2-propanol, butanenitrile and cyclohexanone) with $\varepsilon>$ 18 (Table 1). That solvent dielectric constant $\varepsilon$ is more crucial than solvent refractive index $n$ in affecting the $k_{\mathrm{nr}}$ values of these dyes is corroborated by the significantly superior fit of $y=k_{\mathrm{nr}}$ as a function of $\varepsilon$ [eqn (3)] compared to that as a function $f\left(n^{2}\right)$ [eqn (4)] (Table S6). Very similar results are obtained for 2-Ethyn (Table S6). The solvent effect on $k_{\mathrm{f}}, k_{\mathrm{n} r}, \lambda_{\mathrm{abs}}(\mathrm{max})$ and $\lambda_{\mathrm{em}}(\max )$ of 2-Ph is completely similar to that of 2-Ethyn. An excellent multilinear fit of $y=k_{\mathrm{nr}}$ of 8-Ph according to eqn (2) was found with a positive $d_{\mathrm{SdP}}$ estimate and a ca. 8-fold higher, negative $c_{\mathrm{SP}}$ estimate (Table S6). Higher polarity thus leads to higher $k_{\mathrm{nr}}$ values whereas higher polarizability yields lower $k_{\mathrm{nr}}$ values. These results are in agreement with the higher $k_{\mathrm{nr}}$ values of 8-Ph obtained in highly polar, nonpolarizable solvents (e.g., methanol, acetonitrile, acetone) compared to those in nonpolar, highly polarizable solvents (e.g., chloroform, toluene, chlorobenzene). That solvent polarizability decreases the $k_{\mathrm{nr}}$ values more than that solvent polarity increases them (i.e., polarizability has a higher weight than polarity) is confirmed by the better linear fit of $y=k_{\mathrm{nr}}$ as a function of $f\left(n^{2}\right)$ [eqn (4)] than as a function of $\varepsilon$ [eqn (3)] (Table S6). Finally, the satisfactory fit of $y=$ $k_{\mathrm{nr}}$ of 3-Styryl according to eqn (2) yields a positive $c_{\mathrm{SP}}$ estimate and a ca. 10-fold smaller, negative $d_{\mathrm{SdP}}$ value (Table S6), accounting for the highest $k_{\mathrm{n} r}$ values observed for the most polarizable, nonpolar solvents. That polarizability is the key factor influencing the $k_{\mathrm{nr}}$ values of 3-Styryl is confirmed by the satisfactory linear fit of $y=$ $k_{\mathrm{nr}}$ as a function of $f\left(n^{2}\right)$ [eqn (4)] compared to the unacceptable linear fit vs. $\varepsilon$ [eqn (3)].

For a visual inspection of the general influence of $\varepsilon$ and $f\left(n^{2}\right)$ on the $k_{f}, k_{n r}, \lambda_{\text {abs }}(\max )$ and $\lambda_{\text {em }}(\max )$ values for all the studied derivatives, correlation plots have been included in Figures S11-S14 (ESI).

\section{Quantum Chemical Calculations.}

Computational approaches have been proven useful in determining the excited-state properties of BODIPY dyes. In a previous study, we demonstrated that the BODIPY core is nonplanar at the relaxed $\mathrm{S}_{1}$ geometry. ${ }^{45}$ We have also demonstrated that bulky substituents at the 8-position on the BODIPY ring lead to very distorted, nonplanar geometries in the $\mathrm{S}_{1}$ state, leading to a fast nonradiative decay via a conical intersection. ${ }^{19}$ Lindsey, Holten and coworkers employed the SAC-CI method to investigate phenyl substituents at the 8-position. ${ }^{32}$ They found that in the $S_{1}$ state, rotation around the bond connecting the phenyl group to the BODIPY ring was barrierless, allowing an efficient coupling to a radiationless deexcitation mechanism, giving rise to the low fluorescence quantum yields observed experimentally. Mukherjee and Thilagar investigated substitutions around the BODIPY core with respect to relative stability of the electronic ground states. ${ }^{46}$ They found that alkyl substitutions at the $3 / 5$ positions contributed to a stabilization of the ground-state energy coupled with planar relaxed $\mathrm{S}_{0}$ geometries.

Given in Table 5 are the angles between the pyrrole rings describing the planarity of the BODIPY core (Figure $3)$. All of the substituted boron dipyrromethenes considered follow the same trend of becoming less planar in the $\mathrm{S}_{1}$ state compared to $\mathrm{S}_{0}$, with five of the nine BODIPY derivatives having an angle greater than $10^{\circ}$ at the $\mathrm{S}_{1}$ relaxed geometry. 8-Styryl shows significant distortion in the ground state but particularly in the $S_{1}$ excited state, with an angle of $40^{\circ}$. By comparison to meso-tert-butylBODIPY, ${ }^{19}$ we can predict that 8-Styryl will deexcite via radiationless decay. 
Table 5. Angle between the planes of the pyrrole rings of the BODIPY core at the $S_{0}$ and $S_{1}$ relaxed geometries, calculated using $\omega B 97 X / 6-311 G(d)$.

\begin{tabular}{cccc}
\hline BODIPY molecule & & $\mathrm{S}_{0}$ & $\mathrm{~S}_{1}$ \\
\hline 2-Ph & $0^{\circ}$ & $4^{\circ}$ \\
3-Ph & $9^{\circ}$ & $14^{\circ}$ \\
8-Ph & $7^{\circ}$ & $11^{\circ}$ & $2^{\circ}$ \\
2-Ethyn & $0^{\circ}$ & $9^{\circ}$ & $11^{\circ}$ \\
3-Ethyn & $0^{\circ}$ & $1^{\circ}$ \\
8-Ethyn & $6^{\circ}$ & $7^{\circ}$ \\
2-Styryl & $5^{\circ}$ & $4^{\circ}$ & \\
3-Styryl & $14^{\circ}$ & \\
8-Styryl & & & \\
\hline
\end{tabular}

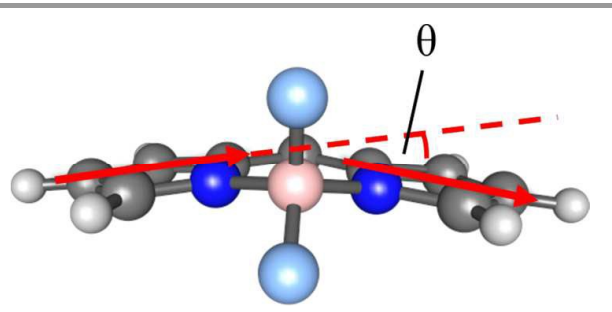

Figure 3. Schematic diagram of the planarity of the BODIPY core, defined as planar when the angle, $\theta$, is equal to zero.

Simulated emission spectra calculated from $a b$ initio molecular dynamics (AIMD) are given in Figure 4. The styryl substituted BODIPYs show large shifts in their calculated emission maxima, with 8-Styryl showing a large shift and a very broad peak. It is worth noting that the calculated emission profiles (and therefore the broadening) are based on the assumption of a normalized emission intensity (i.e., we assume $\Phi=1$ for each given geometry). Given the nonradiative relaxation mechanism expected for 8-Styryl, we would expect the calculated profile to be somewhat different to that given in Figure 3, although we cannot calculate the fluorescence quantum yield directly. For the phenyl-substituted dyes the experimentally observed effect of the substitution position on the emission maximum (Tables 1 and 2) agrees well with the simulated emission spectra. Phenyl substitution at the 8position (8-Ph) exhibits the shortest emission maximum, whereas the longest emission maximum corresponds to the 3-Ph. However, for the phenylethynyl-substituted BODIPYs, the effect of the substitution position is inverted in the simulated spectra when compared to the experimentally obtained spectra. Whereas 2-Ethyn was found to exhibit the shortest emission maximum in the simulation, the experimental spectra showed that this is the compound with the reddest emission among the phenylethynyl-substituted dyes (Table 3). On the other hand, 3Ethyn, the BODIPY with the shortest emission maximum in the experimental spectra (Table 3) shows the largest red shift in the simulation. Furthermore, while for the phenyl-substituted dyes the range of the emission maxima in the simulation is about $50 \mathrm{~nm}$, corresponding to what was found experimentally, this range is for the ethynylphenyl substituted BODIPYs much larger in the simulation $(110 \mathrm{~nm})$ than found experimentally $(5 \mathrm{~nm}$ in toluene). 


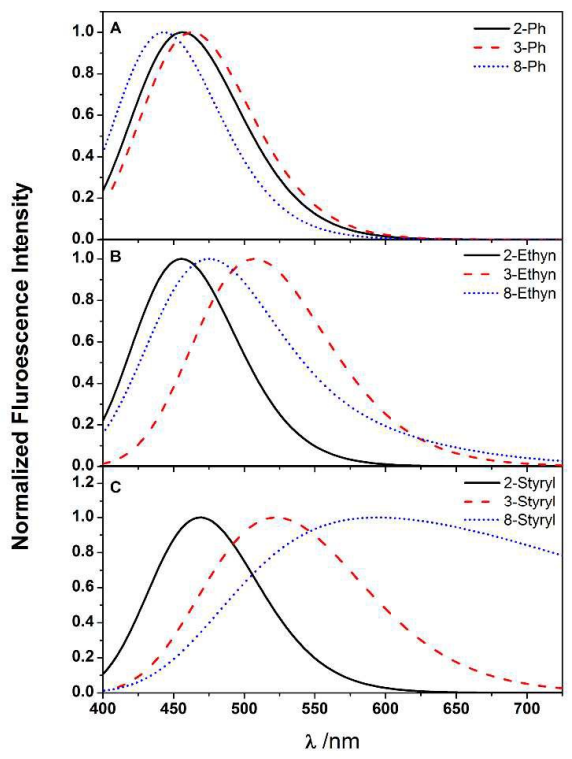

Figure 4. Simulated emission spectra calculated from AIMD trajectories with $\omega B 97 X / 6-311 G(d)$ of (A) phenyl-, (B) phenylethynyl-, and (C) styrylBODIPYs, substituted at the positions 2 (solid lines), 3 (dashed lines), and 8 (dotted lines).

Besides the emission spectra the calculations also yield information on the dipole moments of the different species involved: relaxed ground state, Franck Condon $\mathrm{S}_{1}$ excited state, relaxed $\mathrm{S}_{1}$ excited state, Franck Condon ground state (Table 6). In all cases, except for 2-Styryl, the relaxed $\mathrm{S}_{0}$ dipole moment is higher than the relaxed $\mathrm{S}_{1}$ dipole moment calculated using DFT. For all compounds studied we observe upon excitation, which occurs at the equilibrium geometry of the $\mathrm{S}_{0}$ state, a decrease of the permanent dipole moment. This explains the positive values obtained for $d_{\text {sdp }}$ for $\bar{v}_{\text {abs }}$ of all compounds. For all compounds studied we observe upon emission, which occurs at the equilibrium geometry of the $S_{1}$ state, an increase of the permanent dipole moment. This explains the positive values obtained for $d_{\text {SdP }}$ recovered for $\bar{v}_{\text {em }}$ of the 3- and 8-substituted BODIPYs. The increase of the dipole moment upon emission is however in contradiction with the negative values obtained for $d_{\mathrm{SdP}}$ for 2-Ph and 2-Ethyn. In absorption, the spectral shift of $\bar{v}_{\text {abs }}$ is proportional with $\mu_{0}\left(\mu_{0}-\mu_{\mathrm{E}}\right)$, all dipole moments at the $S_{0}$ equilibrium (relaxed) geometry. Conversely, for emission the spectral shift of $\bar{v}_{\text {em }}$ is proportional with $\mu_{E}\left(\mu_{0}-\mu_{E}\right)$, all dipole moments at the $S_{1}$ equilibrium (relaxed) geometry. ${ }^{47-49}$ In spite of these predictions we could not find any quantitative correlation between $d_{\mathrm{SdP}}$ and either $\mu_{0}\left(\mu_{0}-\mu_{\mathrm{E}}\right)$ or $\mu_{\mathrm{E}}\left(\mu_{0}-\mu_{\mathrm{E}}\right)$.

While solvent polarity is important, there are some interesting features that cannot be assigned to the dielectric constant $\varepsilon$ alone. 3-Ph, for example, displays a fluorescence quantum yield in acetone of 0.895 , while in butanenitrile $\Phi$ increases to 0.99 , despite $\varepsilon$ being approximately equal for the two solvents (20.7 for acetone and 20.3 for butanenitrile). 2-Ethyn exhibits a $\Phi$ value of 0.47 in acetone, and only 0.24 in butanenitrile. In Table 6 the calculated dipole moments of the BODIPY derivatives are given, along with those for acetone and butanenitrile. In all cases, the relaxed $\mathrm{S}_{0}$ dipole moment is higher than the relaxed $\mathrm{S}_{1}$ dipole moment using DFT, except for 2-Styryl. For almost all of the cases observed, high $\Phi$ values are seen when the relaxed $S_{1}$ dipole moment is lower than the dipole moment of the solvent, with the exception of 3-Ph. We speculate that where the relaxed $\mathrm{S}_{1}$ dipole moment is close to (or less than) the dipole moment of the solvent, the conical intersection can be stabilized and hence $\Phi$ becomes significantly less than 1 . Inspection of the experimental data above confirms that these BODIPY derivatives do indeed show a very solvent dependent behavior with respect to the fluorescence quantum yield. 
Table 6. Dipole moments, in Debye, calculated using $\omega B 97 \mathrm{X} / 6-311 \mathrm{G}(\mathrm{d})$. The second column refers to the ground-state relaxed dipole moment, while the fifth column refers to the excited-state relaxed dipole moment. The third column refers to the excited-state dipole moment calculated at the relaxed ground-state geometry, while the fourth column refers to the ground-state dipole moment calculated at the relaxed excited-state geometry.

\begin{tabular}{|c|c|c|c|c|}
\hline \multirow[b]{2}{*}{ BODIPY molecule } & \multicolumn{2}{|c|}{$\mathrm{S}_{0}$ Equilibrium (relaxed) Geometry } & \multicolumn{2}{|c|}{$\mathrm{S}_{1}$ Equilibrium (relaxed) Geometry } \\
\hline & $\mathrm{S}_{0}$ dipole moment & $\mathrm{S}_{1}$ dipole moment & $\mathrm{S}_{0}$ dipole moment & $\mathrm{S}_{1}$ dipole moment \\
\hline 2-Ph & 4.92 & 3.67 & 4.94 & 3.84 \\
\hline 3-Ph & 4.04 & 2.13 & 4.27 & 2.64 \\
\hline 8-Ph & 5.72 & 3.53 & 5.94 & 3.44 \\
\hline 2-Styryl & 5.13 & 4.02 & 5.51 & 5.32 \\
\hline 3-Styryl & 4.05 & 2.45 & 4.06 & 2.71 \\
\hline 8-Styryl & 6.57 & 2.97 & 8.47 & 3.61 \\
\hline 2-Ethyn & 5.34 & 3.35 & 5.55 & 4.69 \\
\hline 3-Ethyn & 4.28 & 2.08 & 4.45 & 1.82 \\
\hline 8-Ethyn & 6.98 & 3.03 & 7.42 & 2.93 \\
\hline
\end{tabular}

\section{Conclusions}

In this work, we have synthesized and characterized, by UV-vis spectrophotometry and steady-state and timeresolved fluorescence spectroscopy, nine BODIPY derivatives substituted with a phenyl, styryl or phenylethynyl group at the 2-, 3- or 8-position, in a large number of solvents. Our data confirm that 3-substitution is beneficial for producing boron dipyrromethenes with sharp absorption bands and high fluorescence quantum yields. All three 3-substituted derivatives (3-Ph, 3-Ethyn and 3-Styryl) showed these highly favorable features. Conversely, substitution at the 2-position yields BODIPY dyes with large Stokes shifts and broad bands, as found in 2-Ph and 2Ethyn. Substitution at the meso-position produces dyes with features similar to the 3-substituted ones, except for meso-phenyIBODIPY 8-Ph. Spectroscopically, the behavior of both 3-Ph and 8-Ph was in general very similar. However, 8-Ph exhibited less red-shifted emission bands and, importantly, phenyl-substitution at the mesoposition remarkably decreased both the quantum yield and fluorescence lifetime through the enhancement of the nonradiative deactivation processes.

\section{Experimental}

Instrumentation.

Absorption spectra were collected using a Perkin-Elmer Lambda 650 UV/Vis spectrophotometer. Spectrally corrected steady-state fluorescence emission spectra were collected on a JASCO FP-6500 or an Edinburgh Instruments FL 980 spectrofluorometer. All absorption and fluorescence emission measurements were carried out using undegassed samples in $5 \times 10 \mathrm{~mm}$ cuvettes (with $10 \mathrm{~mm}$ optical path length for absorption and a $90^{\circ}$ angle setup for fluorescence collection through the shortest side), in a Peltier temperature-controlled cell holder set at $20^{\circ} \mathrm{C}$. Fluorescence quantum yield $\left(\Phi_{x}\right)$ determination was performed according to eqn (5): ${ }^{50-51}$

$\Phi_{x}=\Phi_{r} \times \frac{F_{x}}{F_{r}} \times \frac{1-10^{-A_{r}\left(\lambda_{\mathrm{ex}}\right)}}{1-10^{-A_{x}\left(\lambda_{\mathrm{ex}}\right)}} \times \frac{n_{x}^{2}}{n_{r}^{2}}$

where $x$ and $r$ refer respectively to sample $x$ (i.e., BODIPY derivatives) and reference (standard) fluorophore $r$ with known quantum yield $\Phi_{r} ; F$ denotes the integrated fluorescence spectra, with spectral and inner-filter correction (the latter was minimized by keeping the absorbance below 0.1 , but in cases of small Stokes shift, the correction was needed); $A\left(\lambda_{\text {ex }}\right)$ stands for the absorbance at the corresponding excitation wavelength; and $n$ is the refractive index of the solvent. Rhodamine $6 \mathrm{G}$ dissolved in water was employed as the fluorescence quantum yield reference $\left(\Phi_{r}=0.76\right){ }^{52}$ For each quantum yield determination, eight independent $\Phi_{x}$ measurements were performed, using ( 2 conc. of sample $x) \times(2$ conc. of reference $r) \times\left(2\right.$ excitation wavelengths $\left.\lambda_{\text {ex }}\right)$

Fluorescence lifetimes, $\tau$, were obtained from a $\chi^{2}$-minimization by iterative reconvolution fitting of the convolution of the $\delta$-response function with the instrumental response function to fluorescence decay traces, recorded using a FluoTime200 fluorometer (PicoQuant $\mathrm{GmbH}$ ) working in single photon timing mode. ${ }^{53-55}$ The pulsed excitation source was either a $485 \mathrm{~nm}$ or a $532 \mathrm{~nm}$ diode laser (LDH series from PicoQuant GmbH), 
operated with a PDL-800 driver (PicoQuant) at a pulse repetition rate of $20 \mathrm{MHz}$, except for 8-Ph, whose decay traces were collected at a $40 \mathrm{MHz}$ repetition rate. For each compound in a given solvent, three different fluorescence decay traces were collected at different emission wavelengths, selected by a grating monochromator, after a polarizer set at the 'magic angle'. The fluorescence decay traces were collected over 1320 channels, with a time increment of 36 ps or 18 ps per channel (for $20 \mathrm{MHz}$ or $40 \mathrm{MHz}$ repetition rates, respectively), until they reached $2 \times 10^{4}$ counts in the peak channel. Histograms of the instrument response functions were collected using a LUDOX scatterer.

\section{Quantum chemical calculations.}

Structures of the ground $\left(\mathrm{S}_{0}\right)$ and the first singlet excited $\left(\mathrm{S}_{1}\right)$ state were optimized using unrestricted DFT with the $\omega B 97 X$ functional and the 6-311G(d) basis set. In order to study the first singlet excited state within Kohn-Sham DFT, the maximum overlap method (MOM) was employed to converge the self-consistent field (SCF) procedure to an excited-state solution. In this procedure, an initial set of orbitals for the ground state is generated, then a $\beta$ electron is excited from the HOMO to the LUMO; the MOM procedure then prevents the variational collapse to the ground state within the subsequent SCF calculation. This approach has the advantage that the orbitals are specifically optimized for the state of interest and the transition energies can be calculated using a $\triangle S C F$ approach. This approach is accurate for a large number of states; however, the excitation energy to valence orbitals (i.e. non-Rydberg) leading to open-shell singlet states is usually underestimated. The reason for this deficiency is associated with the use of a single determinant describing a mixed-spin state. The computed excitation energies (and thus gradients) can be improved significantly by applying the Ziegler post-SCF spinpurification correction, eqn (6):

$E=2 E_{\mathrm{S}}-E_{\mathrm{T}}$

where $E$ is the energy of the spin-purified (true) singlet state, $E_{\mathrm{S}}$ is the energy of the spin-mixed state and $E_{\mathrm{T}}$ is the energy of the corresponding triplet state. This approach has been successfully applied previously to the BODIPY core. $^{19,45}$ Solvation was taken into account using the polarizable continuum model (PCM), with a dielectric constant set to 37.5 (acetonitrile).

$A b$ initio molecular dynamics (AIMD) simulations were performed in both the gas phase and solvated phase, using the PCM. All AIMD simulations were run for a total of $10^{4}$ steps, with a time step of 10 a.u. Fock matrix extrapolation was employed, using the last 10 Fock matrices and extrapolated using a $5^{\text {th }}$-order polynomial. Ground-state and excited-state potential energy surfaces were explored using the MOM method outlined above. All DFT calculations were performed with the Q-Chem software.

\section{Acknowledgments}

We acknowledge financial support from the Fonds voor Wetenschappelijk Onderzoek (FWO, grant G.0962.13) and a postdoctoral fellowship to E. D. The authors also thank Belspo for funding through IAP VII-05.

\section{Author contributions}

$\mathrm{NB}, \mathrm{MVdA}, J \mathrm{H}, \mathrm{WD}$ and $A O$ designed research; ED, VL, BV, LCDdR and WD synthesized the compounds; $A O, E D$, MJRR, EGF, LC, EMT and JMAP performed the spectroscopic measurements; NB and MVdA performed the solvatochroism study; DR performed the quantum chemical calculations; AO and NB wrote the draft manuscript; all authors reviewed and edited the final version.

\section{References}

1. R. P. Haugland, The Molecular Probes ${ }^{\circledR}$ Handbook-A Guide to Fluorescent Probes and Labeling Technologies, 11th edn., Life Technologies Corp. , Eugene OR (USA), 2010.

2. G. Ulrich, R. Ziessel and A. Harriman, Angew. Chem. Int. Ed., 2008, 47, 1184-1201.

3. A. Loudet and K. Burgess, Chem. Rev., 2007, 107, 4891-4932. 
4. S. E. Braslavsky, Pure Appl. Chem., 2007, 79, 293-465.

5. L. Bonardi, H. Kanaan, F. Camerel, P. Jolinat, P. Retailleau and R. Ziessel, Adv. Funct. Mater., 2008, 18, 401-413.

6. R. Ziessel, L. Bonardi, P. Retailleau and F. Camerel, C. R. Chim., 2008, 11, 716-733.

7. N. J. Findlay, J. Bruckbauer, A. R. Inigo, B. Breig, S. Arumugam, D. J. Wallis, R. W. Martin and P. J. Skabara, Adv. Mater., 2014, 26, 7290-7294.

8. M. Benstead, G. H. Mehl and R. W. Boyle, Tetrahedron, 2011, 67, 3573-3601.

9. S. P. Singh and T. Gayathri, Eur. J. Org. Chem., 2014, 2014, 4689-4707.

10. N. Boens, V. Leen and W. Dehaen, Chem. Soc. Rev., 2012, 41, 1130-1172.

11. T. Kowada, H. Maeda and K. Kikuchi, Chem. Soc. Rev., 2015, 44, 4953-4972.

12. N. Boens, B. Verbelen and W. Dehaen, Eur. J. Org. Chem., 2015, 2015, 6577-6595.

13. A. B. Descalzo, H.-J. Xu, Z.-L. Xue, K. Hoffmann, Z. Shen, M. G. Weller, X.-Z. You and K. Rurack, Org. Lett., 2008, 10, 1581-1584.

14. L. Zeng, C. Jiao, X. Huang, K.-W. Huang, W.-S. Chin and J. Wu, Org. Lett., 2011, 13, 6026-6029.

15. D.-J. Kang, D.-H. Eom, J.-T. Mo, H.-S. Kim, P. Sokkalingam, C.-H. Lee and P.-H. Lee, Bull. Korean Chem. Soc., 2010, 31, 507-510.

16. S. Yamazawa, M. Nakashima, Y. Suda, R. Nishiyabu and Y. Kubo, J. Org. Chem., 2016, 81, 1310-1315.

17. J. Bañuelos, I. J. Arroyo-Córdoba, I. Valois-Escamilla, A. Alvarez-Hernández, E. Peña-Cabrera, R. Hu, B. Z. Tang, I. Esnal, V. Martínez and I. López Arbeloa, RSC Adv., 2011, 1, 677-684.

18. J. Bañuelos-Prieto, A. R. Agarrabeitia, I. Garcia-Moreno, I. Lopez-Arbeloa, A. Costela, L. Infantes, M. E. Perez-Ojeda, M. Palacios-Cuesta and M. J. Ortiz, Chem. Eur. J., 2010, 16, 14094-14105.

19. L. Jiao, C. Yu, J. Wang, E. A. Briggs, N. A. Besley, D. Robinson, M. J. Ruedas-Rama, A. Orte, L. Crovetto, E. M. Talavera, J. M. Alvarez-Pez, M. Van der Auweraer and N. Boens, RSC Adv., 2015, 5, 89375-89388.

20. G. Sathyamoorthi, J. H. Boyer, T. H. Allik and S. Chandra, Heteroatom Chem., 1994, 5, 403-407.

21. S. Choi, J. Bouffard and Y. Kim, Chem. Sci., 2014, 5, 751-755.

22. A. Schmitt, B. Hinkeldey, M. Wild and G. Jung, J. Fluoresc., 2009, 19, 755-758.

23. I. J. Arroyo, R. Hu, G. Merino, B. Z. Tang and E. Peña-Cabrera, J. Org. Chem., 2009, 74, 5719-5722.

24. B. R. Groves, S. M. Crawford, T. Lundrigan, C. F. Matta, S. Sowlati-Hashjin and A. Thompson, Chem. Commun., 2013, 49, 816-818.

25. C. A. Osorio-Martínez, A. Urías-Benavides, C. F. A. Gómez-Durán, J. Bañuelos, I. Esnal, I. López Arbeloa and E. Peña-Cabrera, J. Org. Chem., 2012, 77, 5434-5438.

26. V. Leen, P. Yuan, L. Wang, N. Boens and W. Dehaen, Org. Lett., 2012, 14, 6150-6153.

27. N. Boens, L. Wang, V. Leen, P. Yuan, B. Verbelen, W. Dehaen, M. Van der Auweraer, W. D. De Borggraeve, L. Van Meervelt, J. Jacobs, D. Beljonne, C. Tonnelé, R. Lazzaroni, M. J. Ruedas-Rama, A. Orte, L. Crovetto, E. M. Talavera and J. M. Alvarez-Pez, J. Phys. Chem. A, 2014, 118, 1576-1594.

28. B. Dhokale, T. Jadhav, S. M. Mobin and R. Misra, Dalton Trans., 2015, 44, 15803-15812.

29. B. Dhokale, T. Jadhav, S. M. Mobin and R. Misra, Chem. Commun., 2014, 50, 9119-9121.

30. K. Krumova and G. Cosa, J. Am. Chem. Soc., 2010, 132, 17560-17569.

31. C. Yu, L. Jiao, H. Yin, J. Zhou, W. Pang, Y. Wu, Z. Wang, G. Yang and E. Hao, Eur. J. Org. Chem., 2011, 2011, 5460-5468.

32. H. L. Kee, C. Kirmaier, L. Yu, P. Thamyongkit, W. J. Youngblood, M. E. Calder, L. Ramos, B. C. Noll, D. F. Bocian, W. R. Scheidt, R. R. Birge, J. S. Lindsey and D. Holten, J. Phys. Chem. B, 2005, 109, 20433-20443.

33. W. Qin, M. Baruah, M. Van der Auweraer, F. C. De Schryver and N. Boens, J. Phys. Chem. A, 2005, 109, 7371-7384.

34. Y. Chen, L. Wan, D. Zhang, Y. Bian and J. Jiang, Photochem. Photobiol. Sci., 2011, 10, 1030-1038.

35. V. Leen, T. Leemans, N. Boens and W. Dehaen, Eur. J. Org. Chem., 2011, 2011, 4386-4396.

36. J. Catalán, J. Phys. Chem. B, 2009, 113, 5951-5960.

37. V. Leen, E. Braeken, K. Luckermans, C. Jackers, M. Van der Auweraer, N. Boens and W. Dehaen, Chem. Commun., 2009, 4515-4517.

38. D.-C. Wang, H.-P. Wang, S. Gao, T.-Y. Zhang and X.-J. Peng, Acta Cryst., 2007, E63, 2238-2239.

39. W. Qin, M. Baruah, A. Stefan, M. Van der Auweraer and N. Boens, ChemPhysChem, 2005, 6, 2343-2351.

40. E. Palao, A. R. Agarrabeitia, J. Bañuelos-Prieto, T. A. Lopez, I. Lopez-Arbeloa, D. Armesto and M. J. Ortiz, Org. Lett., 2013, 15, 4454-4457.

41. R. A. Marcus, J. Chem. Phys., 1965, 43, 1261-1274.

42. B. S. Brunschwig, S. Ehrenson and N. Sutin, J. Phys. Chem., 1987, 91, 4714-4723.

43. G. Verbeek, S. Depaemelaere, M. Van der Auweraer, F. C. De Schryver, A. Vaes, D. Terrell and S. De Meutter, Chem. Phys., 1993, 176, 195-213. 
44. A. Filarowski, M. Kluba, K. Cieślik-Boczula, A. Koll, A. Kochel, L. Pandey, W. M. De Borggraeve, M. Van der Auweraer, J. Catalán and N. Boens, Photochem. Photobiol. Sci., 2010, 9, 996-1008.

45. E. A. Briggs, N. A. Besley and D. Robinson, J. Phys. Chem. A, 2013, 117, 2644-2650.

46. S. Mukherjee and P. Thilagar, RSC Adv., 2015, 5, 2706-2714.

47. V. E. Lippert, Z. Naturforschg., 1955, 10a, 541-545.

48. N. Mataga, Y. Kaifu and M. Koizumi, Bull. Chem. Soc. Jpn., 1955, 28, 690-691.

49. N. Mataga, Y. Kaifu and M. Koizumi, Bull. Chem. Soc. Jpn., 1956, 29, 465-470.

50. B. Valeur and M. N. Berberan-Santos, Molecular Fluorescence. Principles and Applications. , $2^{\text {nd }}$ edn. edn., Wiley-VCH Verlag GmbH, Weinheim (Germany), 2012.

51. J. R. Lakowicz, Principles of Fluorescence Spectroscopy, 3rd edn., Springer, 2006.

52. J. Olmsted, J. Phys. Chem., 1979, 83, 2581-2584.

53. H. Lemmetyinen, N. V. Tkachenko, B. Valeur, J.-i. Hotta, M. Ameloot, N. P. Ernsting, T. Gustavsson and N. Boens, Pure Appl. Chem., 2014, 86, 1969-1998.

54. M. vandeVen, M. Ameloot, B. Valeur and N. Boens, J. Fluoresc., 2005, 15, 377-413.

55. W. Becker, Advanced Time-Correlated Single Photon Counting Techniques, Springer, Berlin (Germany), 2005.

TOC

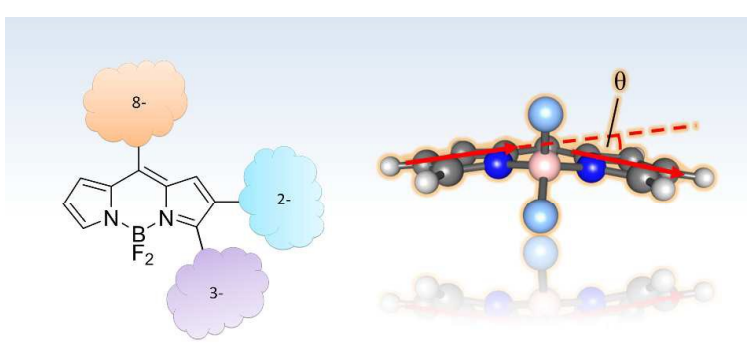

Understanding the spectroscopic properties of BODIPY dyes for a rationale design of tailored fluorescent probes. 